\title{
Towards transdisciplinary decision-support processes in fisheries: experiences and recommendations from a multidisciplinary collective of researchers
}

\author{
Claire Macher ${ }^{1, *}$, Nathalie A. Steins ${ }^{2}$, Marta Ballesteros ${ }^{3}$, Marloes Kraan ${ }^{4}$, Katia Frangoudes ${ }^{5}$, \\ Denis Bailly ${ }^{5}$, Michel Bertignac ${ }^{6}$, Francesco Colloca ${ }^{7}$, Mike Fitzpatrick ${ }^{8}$, Dorleta Garcia ${ }^{9}$, \\ Rich Little ${ }^{10}$, Simon Mardle ${ }^{11}$, Arantza Murillas ${ }^{9}$, Lionel Pawlowski ${ }^{12}$, Manuelle Philippe ${ }^{5}$, \\ Raul Prellezo ${ }^{9}$, Evelina Sabatella ${ }^{13}$, Olivier Thébaud ${ }^{1}$ and Clara Ulrich ${ }^{14}$ \\ ${ }^{1}$ Ifremer, Univ Brest, CNRS, UMR 6308, AMURE, Unité d'Economie Maritime, IUEM, Plouzane, France \\ ${ }^{2}$ Wageningen Marine Research, IJmuiden, The Netherlands \\ ${ }^{3}$ Fisheries Socioeconomic Department, Centro Tecnologico del Mar-Fundacion CETMAR, Vigo, Spain \\ ${ }^{4}$ Wageningen Economic Research, The Hague, The Netherlands and Environmental Policy Group, Wageningen University, Wageningen, \\ the Netherlands \\ ${ }^{5}$ Univ Brest, Ifremer, CNRS, UMR 6308, AMURE, IUEM, Plouzane, France \\ ${ }^{6}$ Ifremer, Unité Sciences et Technologies Halieutiques, Plouzane, France \\ 7 Stazione Zoologica di Napoli Anton Dohrn, Integrative Marine Ecology Department, Naples, Italy \\ ${ }^{8}$ Irish Observer Network Ltd \\ 9 AZTI, Txatxarramendi Ugartea z/g, Sukarrieta 48395, Spain \\ ${ }^{10}$ CSIRO Oceans \& Atmosphere, Hobart, Australia \\ 11 Fishor Consulting, Portsmouth, UK \\ ${ }^{12}$ Ifremer, Laboratoire de Technologies et Biologie Halieutiques, Lorient, France \\ 13 NISEA, Fishery and Aquaculture Research Organisation, Salerno, Italy \\ ${ }^{14}$ DTU Aqua, National Institute of Aquatic Resources Technical, University of Denmark, Charlottenlund, Denmark
}

Received 23 November 2020 / Accepted 19 April 2021

Handling Editor: Dorothy Dankel

\begin{abstract}
The shifting policy focus towards Ecosystem Based Management in Fisheries (EBFM) requires the integration of knowledge and disciplines and the engagement of stakeholders to support decisionmaking processes. Scientists contribute to this through (i) participatory research projects, (ii) stakeholder partnerships and (iii) institutional scientific advice processes. Understanding the role of scientists in such processes, the nature of the interactions between scientists, stakeholders and managers in knowledge integration and the link between science and policy is an emerging field of research addressing transdisciplinary challenges. In 2018, Ifremer-UMR AMURE organized the workshop 'Science, Partnership and Decision-support in Fisheries' bringing together international scientists from natural and social sciences to conduct a review based on twenty concrete case studies. Findings indicate that science-stakeholdermanager partnerships for decision-support in fisheries can play an essential role in the transition to EBFM. To foster this transition, eight recommendations are presented that cover the roles of the different participants, the expectations of partnerships, capacity building, the integration of the social sciences, and funding structures. Further, it is recommended that future research and innovation framework programmes into sustainable fisheries and other ocean uses should explicitly include mechanisms to foster transdisciplinary approaches and the development of best practices. Building-up networks and developing reflexive approaches to review experiences and practices for transdisciplinary approaches in EFBM decision-support will contribute to design the next generation transdisciplinary platforms and generating actionable knowledge towards EBFM.
\end{abstract}

Keywords: Ecosystem-based approach to fisheries management / participatory approach / stakeholder engagement / transdisciplinary approaches / role of science / collaborative research

\footnotetext{
*Corresponding author: claire.macher@ifremer.fr
} 


\section{Introduction}

The shifting policy focus in European fisheries from single species management towards Ecosystem Based Fisheries Management (EBFM) has led to changes. It has triggered a greater integration of ecological, economic and social dimensions in advice and a stronger engagement of stakeholders in data collection, research and decision-support processes (Pikitch et al., 2004; McLeod et al., 2005; Leslie and McLeod, 2007; Wilson, 2009). In EBFM, interactions between the social and ecological system play a key role. The consideration of different interests, characterised by diverse underlying goals, requires making trade-offs (Funtowicz and Ravetz, 1993, Berkes and Folke, 2000). This diversity and the complexity of the systems to be managed calls for crossdisciplinary research incorporating social sciences in natural resource management (Robinson et al., 2012) and transdisciplinary approaches towards integration of academic and practitioner's knowledge (Mauser et al., 2013; Lang et al., 2012; Mason et al., 2017; Blythe et al., 2017; Tress et al., 2004, Cvitanovic et al., 2015, Tengö et al., 2014; Ely et al., 2020; Österblom et al., 2020). In this context, stakeholder engagement in both the decision-making and the decision- support system is essential (Gray, 2005; Berghöfer et al., 2008; Wilson, 2009; Mackinson et al., 2011; Reed, 2008; Röckmann et al., 2012, 2018; Thebaud et al., 2014; Sampedro et al., 2017; Macher et al., 2018a; Gray and Hatchard, 2008; Jentoft and Chuenpagdee, 2009; Steins et al., 2020).

Approaches involving multiple stakeholders and scientists in knowledge production and evaluation of management strategies have increased in recent years driven by expected societal impact, acknowledgement of the added value of meaningful stakeholder engagement in support of marine resource management and funding incentives (Gray, 2005; Gray and Hatchard, 2008; Wilson, 2009; Jentoft and Chuenpagdee, 2009; Berghöfer et al., 2008; Reed, 2008; Mackinson et al., 2011; Röckmann et al., 2012, 2018; Malvarosa et al., 2019; Sampedro et al., 2017; Macher et al., 2018a; Ballesteros et al., 2018; Dickey-Collas and Ballesteros, 2019; ICES, 2018, 2019; Holm et al., 2020). However, Gray and Hatchard (2008) point out that stakeholder participation (SP) in EBFM is characterised by complex linkages in the decision-making process. Such linkages are mainly instrumental. SP ensures that EBFM relies on the best knowledge on shared objectives, while EBFM enhances SP as it enables access of stakeholders to the decision-making process and more empowerment. Understanding these complex relationships lead to question the role of scientists, stakeholders and decision-makers in EBFM, the mutual benefits of their participation, and the suitability of existing organisational structures to foster transdisciplinary approaches (Cvitanovic et al., 2015; Ely et al., 2020; West et al., 2019). In addition, they underline the barriers to integrating different disciplines and sources of knowledge within and outside academia, diverging views on priorities (Mason et al., 2017), conceptual, methodological or philosophical challenges towards integration across disciplines (Eigenbrode et al., 2007; Ely et al., 2020), challenges to co-creation of knowledge for sustainability (Mauser et al., 2013, Österblom et al., 2020), different perceptions of the benefit of integration
(Mackinson et al., 2011) as well as institutional barriers preventing accessibility of science to decision-makers (Cvitanovic et al., 2015).

Traditionally, scientists have provided evidence and advice for decision-making by policy-makers and managers. The plurality of the challenges ahead with the implementation of EBFM (including multi-species management, consideration of biological, economic and social dimensions, and inclusion of stakeholders' knowledge) calls, however, for an active involvement of scientists and stakeholders in the decisionsupport process. Scientists are increasingly involved in the science-policy interface by integrating different sources of knowledge and co-creating knowledge with stakeholders and in the link between knowledge (co-)production and use (Cvitanovic et al., 2016). These new demands on the role of scientists bring about challenges as scientist may, for instance, not be used to nor trained to work across disciplines or with stakeholders. Advancing towards EBFM requires reflexive methodologies (Popa et al., 2015) to review roles (including new roles) of each partner, and analyse the positioning of scientists in stakeholders' engagement and the decisionsupport process appropriately. Most studies on the (changing) role of scientists have, however, not been based on empirical analysis (Spruijt et al., 2014).

In fisheries, the role of scientists in decision-support processes and how they interact with stakeholders is gaining increased attention. This is linked directly to the changing context of the democratisation of knowledge, where fisheries stakeholders are increasingly involved in (co)producing knowledge in support of management and in resource use negotiation (Steins et al., 2020; Mangi et al., 2018; Mackinson and Middleton, 2018; Thompson et al., 2019), and the realisation that EBFM implementation requires transdisciplinary approaches. The literature focuses on various aspects, including development of methodology, tools and guidelines for stakeholder engagement (Röckmann et al., 2015; Kraan et al., 2014; Voinov and Bousquet, 2010; Sampedro et al., 2019; Macher et al., 2018a; Johnson and Van Densen, 2007; Steins et al., 2020), protocols for integrating fisher knowledge into the decision-support process (Mangi et al., 2018; ICES, 2019), and the role of international science institutions and multi-stakeholder advisory bodies in EBFM in improving uptake of science (Wilson, 2009; ICES, 2018; Ballesteros et al., 2018; Dankel et al., 2016; Vielmini et al., 2017). What is lacking, is experience-based guidance and reflexive approaches to explore roles of fisheries scientists and how interactions between scientists from multiple disciplines, decision-makers or managers and stakeholders from industry and from other sectors could be operationalised towards effective EBFM. To this end, Ifremer-UMR AMURE ${ }^{1}$ organised an international, multidisciplinary workshop 'Science, Partnership and Decision-support in Fisheries' (SciPaDe).

SciPaDe conducted an original review of the experiences of researchers in multi-stakeholder decision-support projects

\footnotetext{
${ }^{1} \mathrm{~A}$ joint research unit in social sciences and humanities focused on the sea https://www.umr-amure.fr/
} 
and lessons from 20 concrete case studies in different European regions as well as in Australia. This paper summarizes the main results and discussion from this workshop. It reviews the roles of scientists, - decision-makers and -stakeholder partnerships in knowledge integration and information flow from science to decision-making and explores what can be gained from the integration of knowledge and practices crossing the boundaries through transdisciplinary approaches. It proposes directions for further research and highlights the need to promote transdisciplinary platforms and experience sharing towards EBFM.

\section{Conceptual framework}

A brief literature overview on the roles of scientists in decision-making processes and on participatory research is first presented, to put results of the SciPaDe workshop in perspective of existing knowledge.

Hoppe $(2005,2009)$ identifies seven groups of "boundary roles" in the science-policy interface: (1) rational facilitators of accommodation feeding the political process with sound science and stakeholders' knowledge,(2) knowledge brokers exploiting opportunities of available knowledge in the political process, (3) megapolicy strategists claiming for critical examination of strategic policy guidelines and assumptions based on science, (4) policy analysts providing evidence-based information for decision, (5) policy advisors incorporating best available and usable knowledge to advise on acceptability and feasibility of options, (6) post-normal scientists creating and institutionalizing collaborations between scientists and policymakers for integrated assessment, and (7) deliberative proceduralists embedding open-debates between parties into procedures. Other typologies are presented by Pielke (2007) and adapted by Röckmann et al. (2015). The latter author identifies six "extreme roles" of scientists in decision-making: (1) the pure scientist with no direct interaction with decisionmakers, (2) the science arbiter providing expert judgement, (3) the issue advocate interacting with decision-makers to select options, (4) the honest broker proposing new alternatives, (5) the scientist's non role, when scientific evidence is irrelevant, decision-making is political only, and (6) the scientist's strong role, when decision-making is based on scientific information only. Based on an analysis of the roles of scientists in the development and implementation of pelagic management plans, Dankel et al. (2016) developed an applied typology. They identify four different roles of scientists in the process with scientists being (1) developers (e.g. of quota setting mechanisms), (2) reviewers, (3) judges (e.g. of the ability for the management plan to reach management objectives) or (4) messengers. They also show that the same fisheries scientists can play several roles throughout the process, and that in practice it may be difficult to separate them. Being clear about "which hat scientists are wearing" is important to avoid confusion on the plurality of scientists' roles amongst decision-makers and stakeholders, and to ensure that credibility of science is not compromised (Dankel et al., 2016). While Dankel et al. (2016) provide a grounded typology in the context of European fisheries, most of the work done on the role of scientists in environmental sciences has, however, remained theoretical (Spruijt et al., 2014). In the context of
EBFM, complexities involved call for analyses of these evolving roles based on concrete experiences.

The role of scientists in decision processes is connected to participatory research through the interplay between scientists, stakeholders and decision-makers. Analysing governance of decision-support and decision-making processes requires methodologies for assessing interactions and studying more specifically the roles of each of the stakeholders and their interactions. Kraan et al. (2014) describe how stakeholder involvement in research requires a deliberate methodology, looking at the roles (tango) played by scientists and stakeholders in joint knowledge production. Röckmann et al. (2015) suggest the "interaction triangle" as a tool to assess what level of interactions is needed (based on the context) between scientists, decision-makers and other actors. Barreteau et al. (2010) propose a framework to make the roles of participants explicit. Other authors are interested in the different forms of relationships between stakeholders, decision-makers and scientists in participatory approaches (such as participatory modelling approaches) developed for decision-support (reviewed by Voinov and Bousquet, 2010 and described for example in Sampedro et al., 2017; Macher et al., 2018a). Within the European advisory system, Ballesteros et al. (2018) identify a more proactive role of te International Council for the Exploration of the Sea (ICES) in integrating stakeholder interactions. Dickey-Collas and Ballesteros (2019) explain that the question is no longer "if stakeholders should be engaged in decision-making processes" but "how to organize the conditions for their participation to ensure the credibility and legitimacy of the information produced".

The challenges of developing co-creation processes that allow for the integration of multiple sources of knowledge are not yet fully addressed. Ramirez-Monsalve et al. (2016) highlight the road ahead to develop the necessary interactions for EBFM implementation through strong institutional support. Cvitanovic et al. (2019) urge to develop procedures and codes of conduct for stakeholder engagement, monitoring and managing these commitments. The goal is maintaining and developing trust and dialogue between partners (Reed et al., 2014), ensuring transparency of participation (Röckmann et al., 2018), avoiding disappointments (described in Barreteau et al., 2010), or risks of recovery of work by interest groups (OECD, 2016). Steins et al. (2020) emphasise that participation and collaboration of stakeholders in research requires that such partnerships are embedded in institutional structures for science and resource management. This may be particularly challenging in multi-level governance situations such as in the EU. If science-stakeholder partnerships take place in isolation from the institutional framework or there is a weak connection, it is unlikely they will progress beyond being a tool for improving relationships among those involved, and may eventually result in reducing support for collaboration and eroding stakeholder trust (Steins et al., 2020; Holm et al., 2020).

The way stakeholder engagement in decision-support systems and decision-making processes is shaped, influences the roles that scientists may have in these processes, and hence any subsequent analysis. Reed (2008) classifies participation of stakeholders in environmental management according to the degree, the nature and the objective of participation. 
Cvitanovic et al. (2019) highlight a variety of forms of involvement of stakeholders in participatory research, from consultation where stakeholders provide input, to co-production where stakeholders are partners. Based on the typologies of Biggs (1989) and Probst et al. (2003), Barreteau et al. (2010) propose a typology of stakeholder engagement in research that distinguishes four modes of participation in terms of stakeholder involvement and ownership of the process (shared or not): (1) Contractual: only one actor has decisionmaking power over most decisions made in the process. Other actors participate in activities defined by this actor by being formally or informally engaged to produce aid and services; (2) Consultative: most decisions are made by a single actor but the focus is on consultation and gathering information from other actors; (3) Collaborative: different actors collaborate on an equal footing for the production of knowledge and decisionmaking with however a responsibility over the research process which is not fully shared; (4) Collegiate: different actors work together as colleagues or partners. Responsibility and decision-making power are shared equitably among partners and decisions are made by agreement and consensus among partners.

This paper uses the above typologies of the roles of scientists by Hoppe (2009) and Pielke (2007) and of participation in research by Barreteau et al. (2010) as a basis for exploring interactions between scientists, stakeholders and decision-makers in the case studies. Throughout, participatory approaches are referred to as methods and processes developed to engage stakeholders in the decision-support process. Partnership refers to places/arenas/fora of interactions between partners where the roles of each partner are explicitly considered. Partnerships, as institutions, either can exist through an informal agreement between partners or be fully formalized. Sensu stricto, partnerships are characterized by equal roles played by each partner and an agreement to advance their mutual interest.

\section{Methods}

The SciPaDe workshop was held in Brest, France, in January 2018. The workshop brought together a multidisciplinary group of 19 scientists from fisheries and marine research institutes in Europe and in Australia with background in biology (4), economics (6), mathematics/bio-economic modelling (3), social and political sciences (6). The objective was to explore the role of scientists and collaborations between scientists, stakeholders and decision-makers towards implementation of transdisciplinarity and EBFM. The workshop was limited to participation by scientists only to allow for a reflexive approach, not influenced by the presence of decisionmakers or stakeholders. Participants were personally invited by the organisers (the lead author assisted by the AMURE team) based on their backgrounds and practical experience in decision-support processes and participatory approaches in fisheries research. Scientific disciplines and geographic area of expertise were taken into account to form a group of participants covering a large range of regional management contexts and bringing different points of view. The workshop was not audio recorded, but written notes from all discussions were taken by the organisers. A workshop report is available (Macher et al., 2018b) ${ }^{2}$.

Discussions focused on the context, content and lessons learnt from concrete experiences in support of fisheries management, the roles held by scientists in the projects and the links between scientists and stakeholders, and between scientists and decision-makers. Analysis focused on decision-support processes and interactions developed under authorities' requests, the European Union (EU) Impact Assessment (IA) processes for new regulations, stakeholders' demands for IA of management strategies, or collaborations and methods for IA developed under research projects. The scope of decision-makers and policy officers was narrowed to managers, excluding the "political authorities" in charge of the final decisions (e.g. ministers and parliament members as elected representatives) while stakeholders mainly referred to the fishing industry (Producer Organizations, fishermen and their representatives) in the projects reviewed.

SciPaDe followed a step-wise format consisting of three steps.

\subsection{Step 1: Knowledge and information sharing}

The first step focused on systematic qualitative information sharing on the collaborations between scientists, stakeholders and/or decision-makers participants experienced for identified decision-support project(s) where strong collaboration was evident. Prior to the workshop, participants filled out a template table (Appendix A) used to collate information on: the decision-support process, including the institutional context, objectives, deliverables and the role of participants, the nature of partnerships, including rationale, parties involved and organisational structures, and lessons learnt, including uptake, benefits, constraints, opportunities and recommendations. Using a common template allowed for: comparison of decision-support processes and participatory approaches used in different case studies, review experiences and views across case studies, disciplines and projects about forms of interactions between scientists and stakeholders and between scientists and decision-makers or managers, analysis of the roles of scientists in decision-support, and exploring the use of results in decision-making and the benefits of participation in terms of process and decision-making. The template focused on processes involved in decision-support projects. Outcomes of partnerships in terms of impacts on the fishery or ecosystem (e.g. fishery recovery) were not evaluated.

During this first step, participants presented their table and shared experiences from the different case studies. Twenty case studies were reviewed through this approach (Tab. 1). Summary tables created from the templates are available as Tables 1-4 and supplementary materials. Tables include

\footnotetext{
${ }^{2}$ Regarding research ethics: None of the information shared was confidential. When referring to stakeholders, participants referred to organisation names and not to names of individual fishers, policymakers or other partners in a project. No formal research ethics approval process was required under this French funding project. The workshop participants were, however, all scientists who followed research ethics commonly used in social science in relation to anonymity of sources in discussions, analysis and reporting.
} 


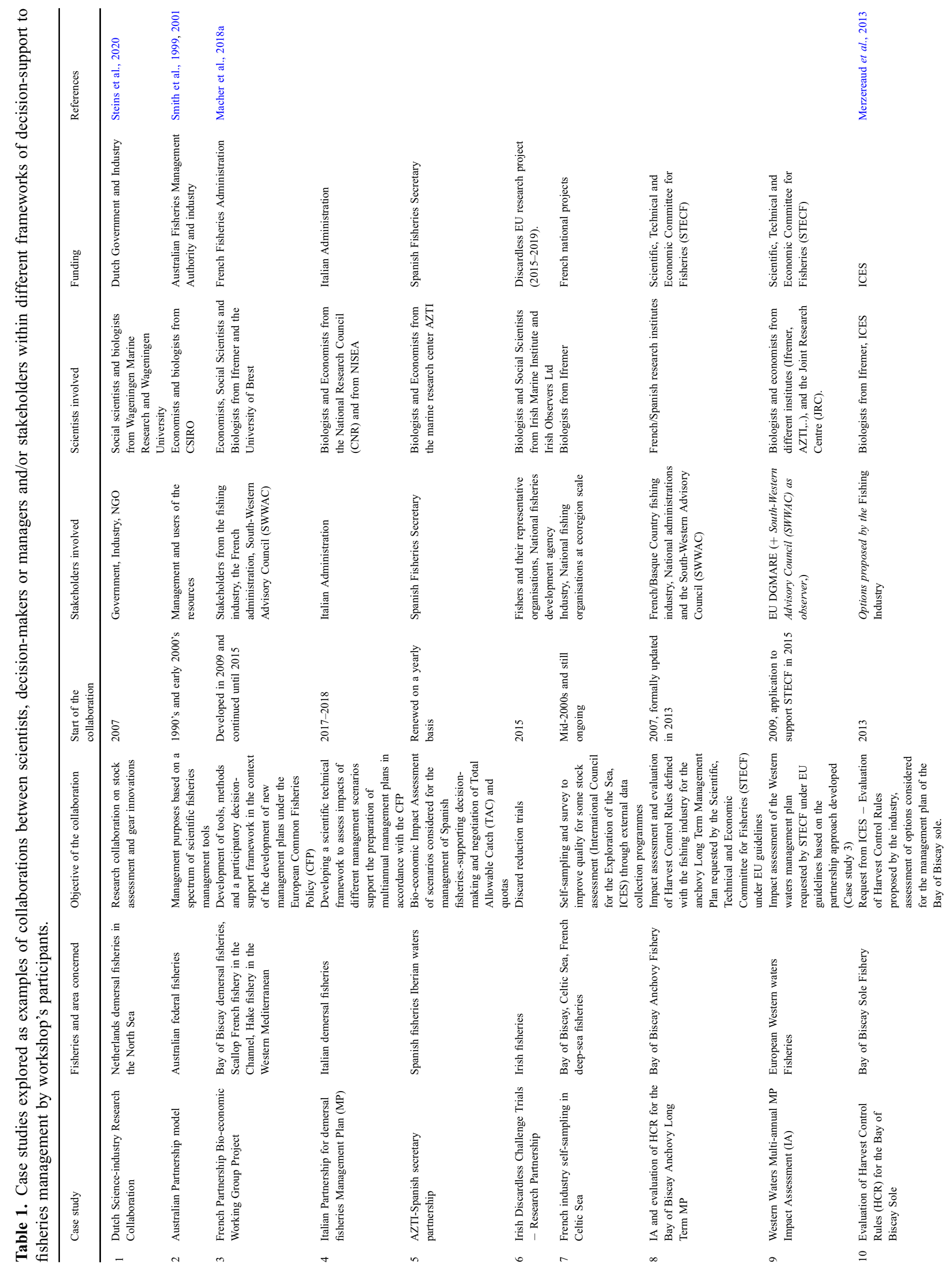




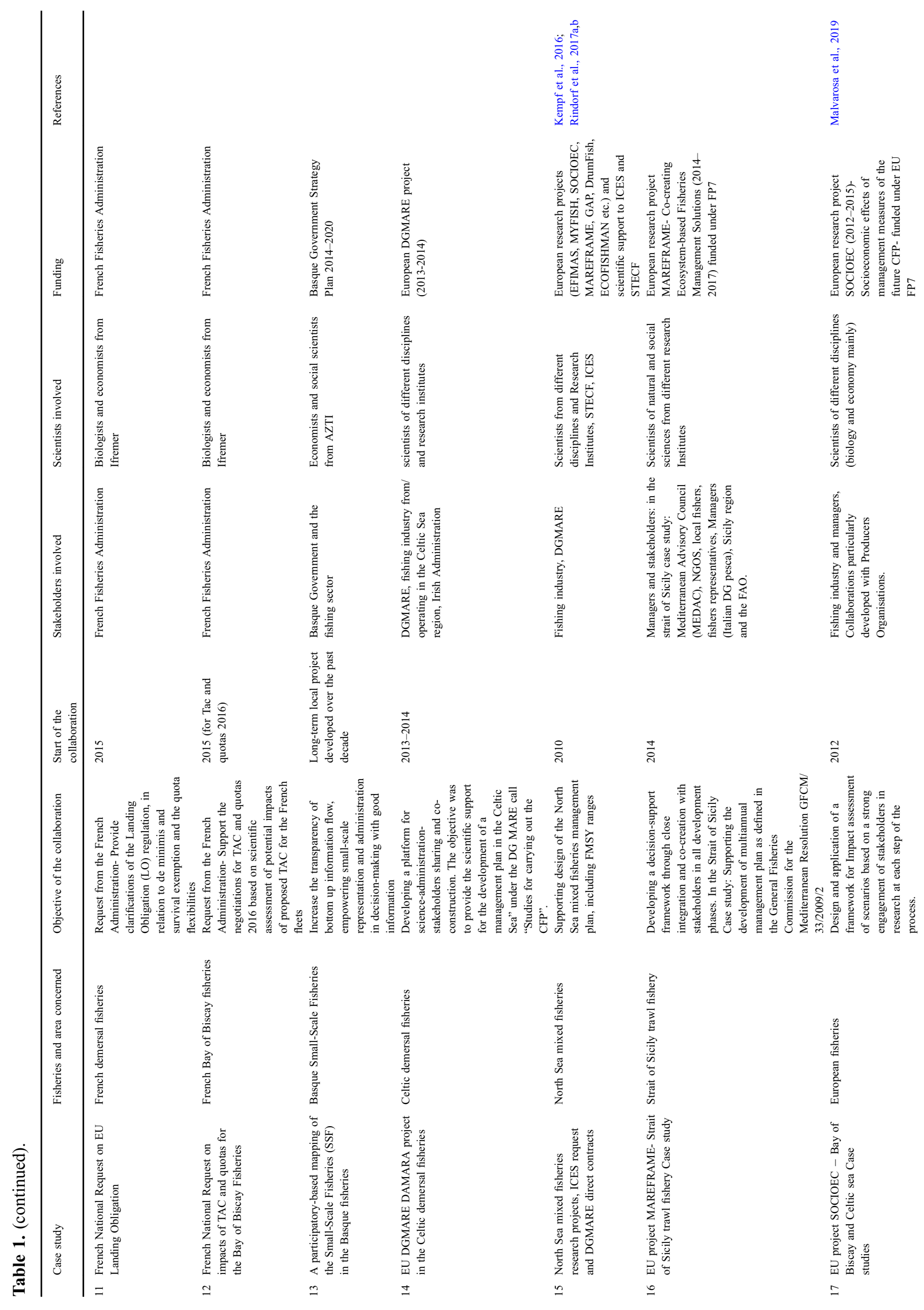

Page 6 of 21 


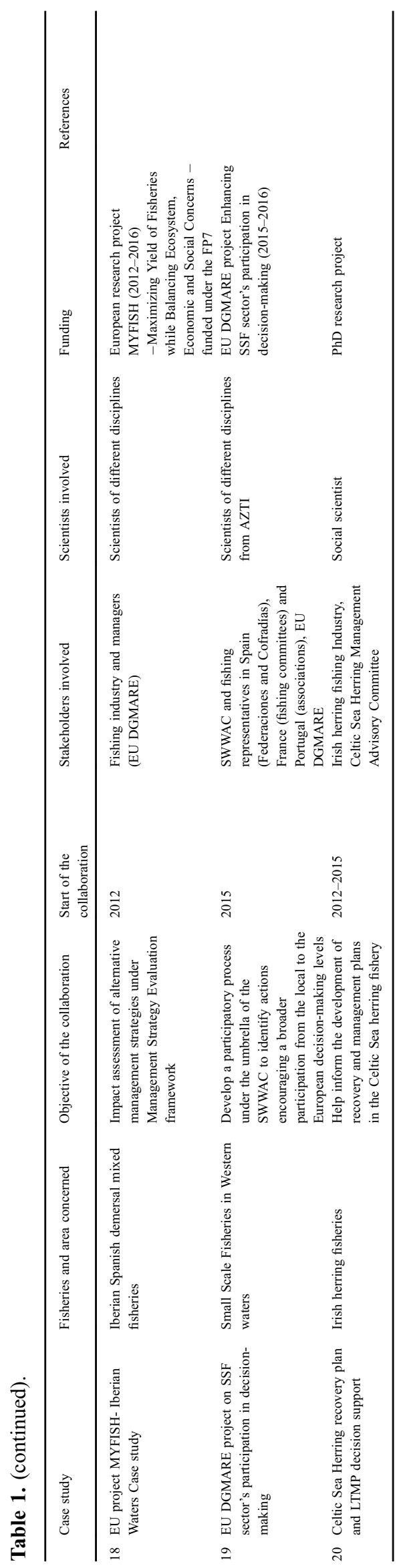

developments and categorizations from the common template provided in Appendix A and filled-in for each case study. Case studies explored are situated in the North Sea, the Celtic Sea, the Bay of Biscay, Iberian waters, the Mediterranean Sea and in Australia (Fig. 1). Not all case studies had an EBFM focus. However, all cases involved changing or new forms of partnerships between science, fishers and other stakeholders in relation to fisheries management support. When debating the role of science in decision-support partnership on the same case studies, in future, the common template (Appendix A and Synthetic tables derived from its analysis) will be a useful tool to ensure different stakeholders reflect on the same aspects of partnership projects.

It should be noted that participants shared experience based on their involvement in multiple collaborations with stakeholders and that different approaches were adopted to report their case studies' experience. As the objective of the project was both to reflect on specific case studies and contexts on the one hand and to explore the role and positioning that each scientist experienced in different case studies on the other hand, some participants provided the template information for each separate project, whereas others focused on the major lessons learnt from their whole experience. Given the varying number of participants between areas represented, some regions reported more collaborations with stakeholders (e.g. Bay of Biscay/Western waters, Celtic seas, Mediterranean) compared to others where in reality there are more (e.g. Netherlands/North Sea, Australia). Where the outcomes of this exercise may not necessarily give a representative image of the number of collaborations in the different regions, it nevertheless allows for a comparison of their diversity. Using a common information provision template, it is important that there are clear instructions on "what is a case study" to ensure consistency. In addition, attention should be paid to the selection of participants to allow for a representative diversity in country experiences. It was found that the different approaches taken by the participants did not create a constraint in the discussions and analysis of experiences, and hence the findings developed in relation to the scientists' perspective.

\subsection{Step 2: Strengths-weaknesses-opportunities- threats (SWOT)}

The workshop's second step consisted of two exercises of SWOT analyses to develop a common vision and diagnostic regarding two major issues in the implementation of EBFM: the decision-support framework implemented, and the interactions and partnerships developed between scientists, stakeholders and decision-makers or managers. Participants were asked to explore Strengths, weaknesses, opportunities and threats towards a good decision-support framework and good interactions or partnerships in line with EBFM. The SWOTs were conducted based on a method of individual contributions through post-it stickers and a pirate ship poster provided in appendix A1 as playful support. This exercise was conducted to elicit the general experiences of each participant across all case studies. Detailed results of the SWOT are synthetized in the workshop report (Macher et al., 2018b). The SWOT provided a shared diagnostic regarding main issues related to decision-support and partnerships towards EBFM. SWOT findings are not explored in detail in this paper, as its 


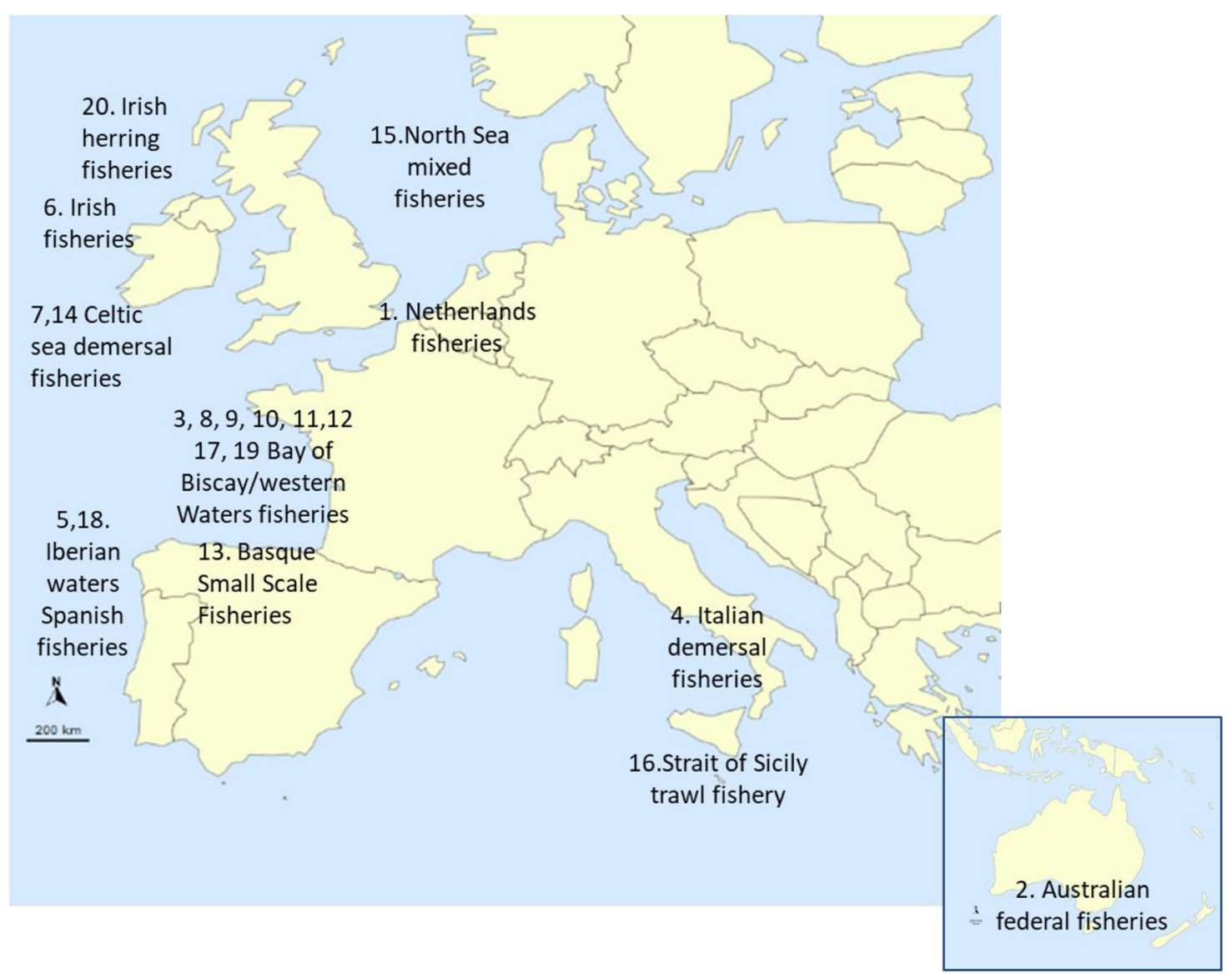

Fig. 1. Map of the case studies.

focus is on lessons learnt from the case studies analysis. Where SWOT findings concur with outcomes from the case study analysis regarding transdisciplinarity and implementation of EBFM, this is highlighted in the results and discussion sections.

\subsection{Step 3: General discussions and collaborative writing process}

During the final step of the workshop, general discussionstook place on the lessons learned from case studies and future directions regarding positions and roles of the interactions between scientists, stakeholders and decision-makers or managers in knowledge integration towards implementation of EBFM. Continuation of the in-depth analysis was carried out after the workshop based on main topics highlighted during the workshop and a post-treatment of the templates' materials provided by participants for each case study. Summary tables (and supplementary materials) were created to summarize information collected and allow for cross-study comparison. A collaborative writing process was initiated, associating participants to the workshop (all listed as co-authors) with two main levels of involvement: i) scientists developing the analyses based on the workshop discussions, the case studies analyses and the literature review (this concerned social scientists of the group and the first author); (ii) scientists contributing to provide information on case studies and feedbacks on cross analyses.

\section{Results}

The findings from SciPaDe based on experience from case studies explored five main topics from scientists' perspectives in relation to the link between science, participatory approaches and decision-support towards EBFM in fisheries: (1) forms of partnerships and interactions, (2) role of scientists, (3) benefits of partnerships, (4) use of results from science in the decision-making process and (5) difficulties encountered to address future collaborations towards EBFM.

These five topics were part of the template used for the review of the case studies. They were also addressed in the SWOT analysis and discussed in relation to the integration of knowledge in decision-support and decision-making processes towards the implementation of EBFM and the attributes for a good partnership between scientific and stakeholders in this context. Figure 2 proposes a schematic representation of knowledge integration and decision-support/decision-making in EBFM and highlights how the first four issues addressed in the results section relate to one another in an inter/ transdisciplinary EBFM context.

Definitions of inter- and transdisciplinarity are derived from Tress et al. (2004) and defined in the glossary. 


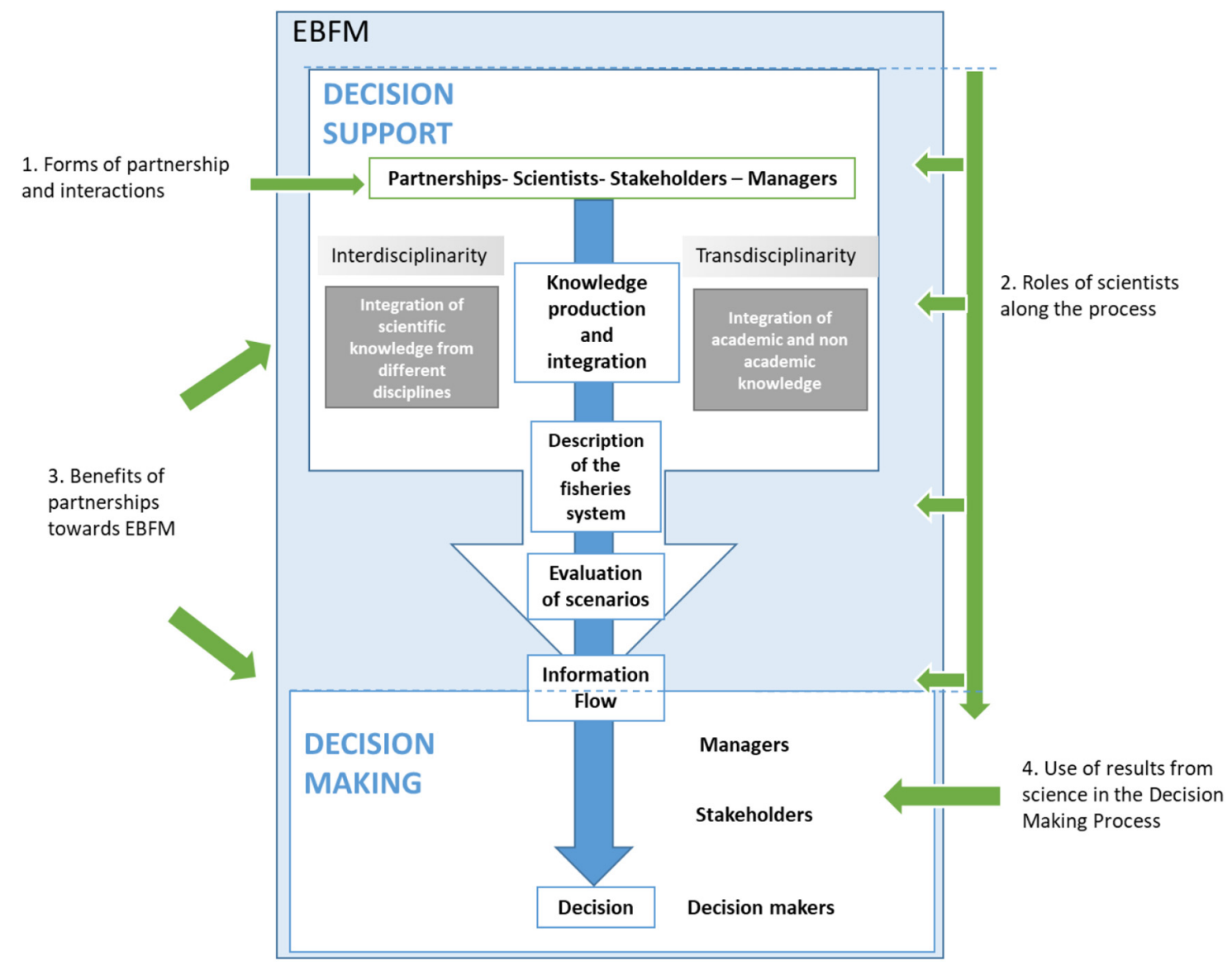

Fig. 2. Diagram of inter-relation between main topics addressed in the workshop towards the implementation of EBFM.

The five topics and their interrelations can be summarised as follows:

- Topic 1-Partnerships and other forms of interactions (in all their diversity), between scientists (of different disciplines), stakeholders (with knowledge on the dynamics and potential responses to change of the socio-ecosystem) and/ or managers, operate at the decision-support step to facilitate/organize knowledge production and integration to provide best available knowledge to support decision. They support the description of the fisheries system and of the interactions existing in the socio-ecosystem and the impact assessment of scenarios and management strategies from a multi-criteria perspective;

- Topic 2-addresses the question of role of scientists all along the process, regarding the production and integration of knowledge in the decision-support process (addressed both in terms of kinds of interactions with stakeholders and in terms of tools and approaches for integration of knowledge) and regarding the information flow from the decision-support sphere to the decision-making arena;

- Topic 3-relates to the benefits of partnerships and interactions to the effective implementation of EBFM (from the scientific point of view);

- Topic 4-deals with the use and uptake of results from science to inform decision-making and information flow from the decision-support process to the decision-making process;
- Topic 5-points out the difficulties highlighted in case studies collaborations.

Results from the exploration of each of these topics based on the case studies reviewed and the participating scientists' experiences are described below.

\subsection{Different forms of partnerships and interactions between scientists, decision-makers and industry}

Scientists experienced various forms of interactions and partnerships with industry and decision-makers or managers in the case studies. Modes of participation and interactions were either contractual, consultative, collaborative or collegiate as classified in Barreteau et al. (2010), depending on ownership of the process (shared or not), and involvement of scientists and stakeholders. Referring to Barreteau's typology, the analysis identifies three forms of decision-support frameworks in the case studies: (1) partnership platforms, (2) institutional scientific advice processes, and (3) contractual projects.

The first form, partnership platforms, are characterized by interactions between partners being explicitly considered and based on equality in roles or agreements between partners to advance their mutual interest. Partnerships could be described as more collegiate forms or working together. They can rely on informal agreement between partners or be fully formalized. 
Table 2. Characteristics and kinds of interactions between scientists-industry-decision-makers in the case studies.

\begin{tabular}{|c|c|c|c|c|c|c|c|c|}
\hline \multirow[b]{2}{*}{ Forms of interactions } & & & \multirow[b]{2}{*}{ Case Study } & \multicolumn{5}{|c|}{ Interactions } \\
\hline & & & & $\begin{array}{l}\text { Scientists/Industry/Decision- } \\
\text { Makers }\end{array}$ & Scientists/Industry & $\begin{array}{l}\text { Scientists/Decision- } \\
\text { Makers }\end{array}$ & Formalization & $\begin{array}{c}\text { Permanence or } \\
\text { continuity (PoC)/ } \\
\text { project related (PR) }\end{array}$ \\
\hline \multirow{7}{*}{ Partnership platforms } & & 1 & Dutch Science-industry Research Collaboration & Yes & Yes & Yes & Yes & PoC \\
\hline & & 2 & Australian Partnership model & Yes & Yes & Yes & Yes & Poc \\
\hline & & 3 & French Partnership Bio-economic Working Group Project & Yes & Yes & Yes & No & PoC \\
\hline & & 4 & Italian Partnership for demersal fisheries Management Plan (MP) & No & No & Yes & Yes & PR \\
\hline & & 5 & AZTI-Spanish secretary partnership & No & No & Yes & No & PoC \\
\hline & & 6 & Irish Discardless Challenge Trials - Research Partnership & No & Yes & No & Yes & PoC \\
\hline & & 7 & French industry self-sampling in Celtic Sea & No & Yes & No & Yes & $P R$ \\
\hline \multirow{5}{*}{$\begin{array}{l}\text { Institutional Decision } \\
\text { support }\end{array}$} & \multirow{2}{*}{ STECF requests } & 8 & IA and evaluation of HCR for the Bay of Biscay Anchovy Long Term MP & Yes & Yes & Yes & No & PR \\
\hline & & 9 & Western Waters Multi-annual MP Impact Assessment (IA) & No & No & Yes & No & PR \\
\hline & ICES requests & 10 & Evaluation of Harvest Control Rules (HCR) for the Bay of Biscay Sole & No & No & Yes & No & $\mathrm{PR}$ \\
\hline & \multirow[b]{2}{*}{ National Requests } & 11 & French National Request on EU Landing Obligation & No & No & Yes & No & PR \\
\hline & & 12 & $\begin{array}{l}\text { French National Request on impacts of TAC and quotas for the Bay of Biscay } \\
\text { Fisheries }\end{array}$ & No & No & & No & PR \\
\hline \multirow{8}{*}{ Contractual Projects } & \multirow{6}{*}{ Research projects } & 13 & $\begin{array}{l}\text { A participatory-based mapping of the Small Scale Fisheries (SSF) in the Basque } \\
\text { fisheries }\end{array}$ & Yes & Yes & Yes & No & PoC \\
\hline & & 14 & EU DGMARE DAMARA project in the Celtic demersal fisheries & Yes & Yes & Yes & Yes & PR \\
\hline & & 15 & North Sea mixed fisheries research projects, ICES request and DGMARE direct & & & & & POR \\
\hline & & 16 & $\begin{array}{l}\text { Contracts } \\
\text { EU project MAREFRAME- Strait of Sicily trawl fishery Case study }\end{array}$ & $\begin{array}{l}\text { res } \\
\text { Yes }\end{array}$ & $\begin{array}{l}\text { res } \\
\text { Yes }\end{array}$ & $\begin{array}{l}\text { res } \\
\text { Yes }\end{array}$ & No & $\mathrm{PR}$ \\
\hline & & 17 & EU project SOCIOEC - Bay of Biscay and Cetic sea Case studies & Yes & Yes & Yes & Yes & PR \\
\hline & & 18 & EU project MYFISH- Iberian Waters Case study & Yes & Yes & Yes & No & $\mathrm{PR}$ \\
\hline & \multirow{2}{*}{ Other Projects } & 19 & EU DGMARE project on SSF sector's participation in decision-making & res & Yes & Yes & No & PoC \\
\hline & & 20 & Celtic Sea Herring recovery plan and LTMP decision support & Yes & Yes & Yes & No & Poc \\
\hline
\end{tabular}

Partnership platforms involve scientists and industry; or scientists, decision-makers and industry; or scientists and decision-makers. From the seven case studies involving this type of interaction, only three illustrate examples of partnerships associating all three partners (scientists, industry and decision-makers): the Dutch Science Industry Research Collaboration, the Australian Partnership Model, and the French Partnership Bioeconomic Working Group Project (see Tab. 1-Cases 1, 2 and 3 respectively, and supplementary materials).

The second form of decision-support frameworks are institutional scientific advice processes. These involve scientists and decision-makers/managers in asymmetrical relationships, relying on contractually defined participation where assessment or advice is expected from scientists. This covers the advice processes undertaken by the European Scientific, Technical and Economic Committee for Fisheries (STECF) or by ICES as well as the national fisheries department requests for decision-support from scientists. Examples include potential impact of Harvest Control Rules (HCR) or Total Allowable Catch (TAC) advice (for example, Tab. 1-Cases 10 and 12) or IA of management plans (Tab. 1, Cases 8 and 9). Industry can also take part in the process at different levels as recommended in the European guidelines for IA (EC, 2009) but this is not necessarily implemented in the process. Interactions can be formalized through guidelines for providing advice or agreements but are not specified at the case studies level.

The third form of decision-support frameworks are contractual projects (research project or studies). These involve scientists, industry and policy-makers through participatory approaches; or, scientists and industry as project partners. Such projects most often occur when cooperation of industry is expected in data collection or experimentation, definition of suitable management objectives and strategies, validation of modelling approaches, or in developing research designs aiming at integrating scientific and expert knowledge and co-constructing scenarios. Interactions are often not fully formalized and opportunistically limited to the project duration. Some forms of continuity tend, however, to emerge in terms of one project followed up by another involving the same partners. EU SOCIOEC (Tab. 1, Case 17), MYFISH (Case 18), DAMARA (Case 14) and MAREFRAME (Case 16) projects belong to this category. Projects involve contractual to consultative forms of participation or collaborative forms at some steps, while their main goal is the provision of knowledge advances pursuing the scientific endeavour.

A synthesis of the main characteristics of the interactions involved in each case study is presented in Table 2.

The analysis also shows differences in the nature and variety of interactions (see supplementary materials for details by case studies). Interactions between scientists and the fishing industry tended to be multi-dimensional and based on co-construction (joint problem definition, scenario building, ..) information sharing and capacity and trust building (Fig. 3a). In contrast, interactions between scientists and decisionmakers were found to be more uni-directional and less diversified (Fig. 3b). They were mostly based on communication of knowledge from scientists to decision-makers (or managers) to answer a question asked by the latter. However, joint problem definition between scientists and managers appear to be manifesting in formal decision-support frameworks. These focus on scoping feasibility of scientific assessment and better matching the political agenda with required scientific support; particularly for management plans where an impact assessment process is mandatory.

\subsection{Various and changing roles of the scientists}

The analysis shows that scientists took on a variety of roles (often combined) in the case studies (Tab. 3). The findings highlight the following roles held by the participants to the workshop in the diverse case studies explored with regards to implementation of EBFM: (1) The classical role of the scientist as a pure producer of knowledge; (2) The scientist as an integrator of knowledge from different disciplines; (3) The scientist as an integrator of academic and empirical knowledge: co-construction of knowledge, fishers knowledge integration; (4) The scientist in charge of the information flow to decision-makers and stakeholders: from knowledge 

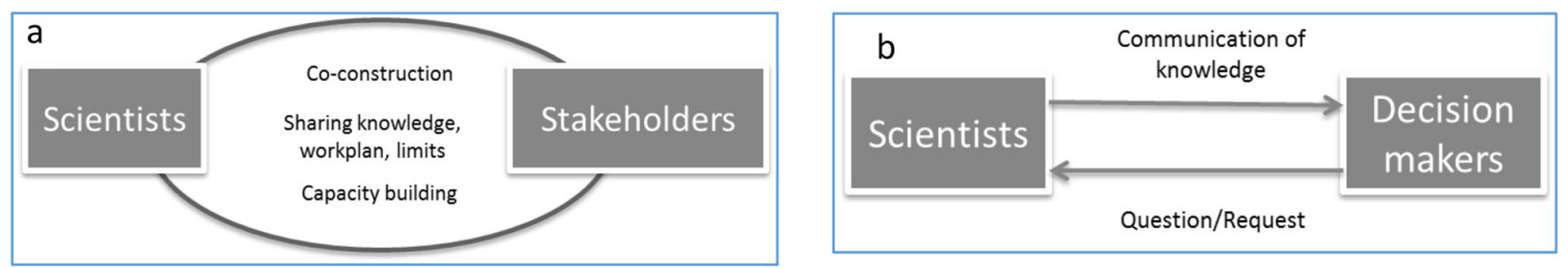

Fig. 3. a: Multi-dimensional interactions between scientists and fishing industry versus; b: Unidirectional interactions between scientists and decision-makers.

Table 3. Roles held by scientists in case studies explored.

\begin{tabular}{|c|c|c|c|c|c|c|c|}
\hline & \multirow[b]{2}{*}{ Case Study } & \multicolumn{6}{|c|}{ Main Roles held by scientists } \\
\hline & & $\begin{array}{l}\text { Knowledge } \\
\text { Production }\end{array}$ & $\begin{array}{c}\text { Inter-disciplinary } \\
\text { Knowledge Integration }\end{array}$ & $\begin{array}{c}\text { Trans-disciplinary } \\
\text { knowledge Integration }\end{array}$ & $\begin{array}{l}\text { Knowledge transfer } \\
\text { and communication }\end{array}$ & $\begin{array}{l}\text { Facilitation/ } \\
\text { coordination of } \\
\text { partnership }\end{array}$ & $\begin{array}{c}\text { Policy } \\
\text { Advice/support }\end{array}$ \\
\hline 1 & Dutch Science-industry Research Collaboration & & & & & & \\
\hline 2 & Australian Partnership model & & & & & & \\
\hline 3 & French Partnership Bio-economic Working Group Project & & & & & & \\
\hline 4 & Italian Partnership for demersal fisheries Management Plan (MP) & & & & & & \\
\hline 5 & AZTI-Spanish secretary partnership & & & & & & \\
\hline 6 & Irish Discardless Challenge Trials - Research Partnership & & & & & & \\
\hline 7 & French industry self-sampling in Celtic Sea & & & & & & \\
\hline 8 & IA and evaluation of HCR for the Bay of Biscay Anchovy Long Term MP & & & & & & \\
\hline 9 & Western Waters Multi-annual MP Impact Assessment (IA) & & & & & & \\
\hline 10 & Evaluation of Harvest Control Rules (HCR) for the Bay of Biscay Sole & & & & & & \\
\hline 11 & French National Request on EU Landing Obligation & & & & & & \\
\hline 12 & French National Request on impacts of TAC and quotas for the Bay of Biscay Fisheries & & & & & & \\
\hline 13 & A participatory-based mapping of the Small Scale Fisheries (SSF) in the Basque & & & & & & \\
\hline 14 & EU DGMARE DAMARA project in the Celtic demersal fisheries & & & & & & \\
\hline 15 & North Sea mixed fisheries research projects, ICES request and DGMARE direct & & & & & & \\
\hline 16 & EU project MAREFRAME- Strait of Sicily trawl fishery Case study & & & & & & \\
\hline 17 & EU project SOCIOEC - Bay of Biscay and Cetic sea Case studies & & & & & & \\
\hline 18 & EU project MYFISH- Iberian Waters Case study & & & & & & \\
\hline 19 & EU DGMARE project on SSF sector's participation in decision-making & & & & & & \\
\hline 20 & Celtic Sea Herring recovery plan and LTMP decision support & & & & & & \\
\hline
\end{tabular}

production to synthesis, communication and use; (5) The scientist as a facilitator for participation; (6) The scientist as a policy advisor.

These roles intersect the boundary roles of rational facilitators, knowledge brokers (or integrators), policy advisors, and post-normal scientists identified in Hoppe (2005). However, more importance is given to the roles of facilitation at the science-policy and science-society interface and to integration of various kinds of knowledge in the context of transition to EBFM and the necessary transdisciplinarity. SciPaDe found these roles to be diverse and changing according to project, situation and demand, and even evolving within the same project with scientists being producer and integrator of knowledge at a step of the project and policy advisor based on results of the project in institutional framework of decision-support (e.g. In the French bioeconomic Partnership working Group, the Italian partnership or the Azti Spanish Secretary Partnership for example).

While scientists usually took the role of pure producers of knowledge, they also played new roles compared to existing referenced typologies (see Sect. 2): from producers of knowledge and advisors, scientists have become (1) facilitators of the integration of various kinds of knowledge, (2) guardians of the transparency of advice or knowledge provided and (3) guardians of the process of their production. Their traditional science and advisory roles have evolved into roles of knowledge brokers, roles of facilitators (or post-normal scientists) involved in participatory research (Hoppe, 2005), roles of science arbiters, honest brokers or even issue advocates (Röckmann et al., 2015). The evolution takes place along the gradient proposed by Turnhout et al. (2013) from limited to strong interactions between production and use of knowledge. Examples range from pure scientists with low interactions with users of the knowledge to the producer of participatory knowledge with strong interactions with the sphere of use.

The role of integrating academic and empirical knowledge (from fishers or fisher representatives) towards transdisciplinary approaches (see Tengö et al., 2014; Stephenson et al., 2016; Chuenpagdee and Jentoft, 2019; Mackinson et al., 2011) was also identified as a major issue and is illustrated in case studies 3,13 or 17 for example where participatory approaches were developed for transdisciplinary knowledge integration. New roles of scientists at the disciplinary interface, at the science/policy interface or at the science/society interface were found challenging by a number of participants for several reasons: i) they were not used to working with scientists from other disciplines or with stakeholders, ii) they wanted to focus on pure science while funding requirements demand societal impact (more applied science), iii) there was a lack of trust in data collected by stakeholders like fishers (while this is a way to deal with costefficiency and fisher support for science and policy), or iv) there was a lack of recognition of social science with social 
Table 4. Benefits/advantages (in terms of process and decision-making) of partnerships and participatory approaches developed in case studies from scientific perspective (4-A), and assessment of use of results (4-B).

\begin{tabular}{|c|c|c|c|c|c|c|c|}
\hline & \multirow[b]{2}{*}{ Case Study } & \multicolumn{4}{|c|}{ 4-A. Benefits/Advantages of partnerships } & \multirow[b]{2}{*}{$\begin{array}{l}\text { Improvement of } \\
\text { gouvernance, capacity } \\
\text { and participation of } \\
\text { stakeholders in the } \\
\text { decision-support } \\
\text { process }\end{array}$} & \multirow[b]{2}{*}{$\begin{array}{l}\text { 4-B. Use of results for } \\
\text { decision-making }\end{array}$} \\
\hline & & $\begin{array}{l}\text { Development of mutual } \\
\text { trust and Increasing } \\
\text { transparency and } \\
\text { legitimacy of tools and } \\
\text { scientific evidence }\end{array}$ & $\begin{array}{l}\text { Improvement of data } \\
\text { quality and availability, } \\
\text { and validation of } \\
\text { models }\end{array}$ & $\begin{array}{l}\text { Integration of knowledge, } \\
\text { facilitation of information } \\
\text { flow and structuring } \\
\text { dialogue }\end{array}$ & $\begin{array}{c}\text { Increased salience, } \\
\text { uptake and use of } \\
\text { science to support } \\
\text { decisions }\end{array}$ & & \\
\hline 1 & Dutch Science-industry Research Collaboration & & & & & & Direct \\
\hline 2 & Australian Partnership model & & & & & & Direct \\
\hline 3 & French Partnership Bio-economic Working Group Project & & & & & & Indirect \\
\hline 4 & Italian Partnership for demersal fisheries Management Plan (MP) & & & & & & Direct \\
\hline 5 & AZTI-Spanish secretary partnership & & & & & & Direct \\
\hline 6 & Irish Discardless Challenge Trials - Research Partnership & & & & & & Not used \\
\hline 7 & French industry self-sampling in Celtic Sea & & & & & & Indirect \\
\hline 8 & IA and evaluation of HCR for the Bay of Biscay Anchovy Long Term MP & & & & & & Direct \\
\hline 9 & Western Waters Multi-annual MP Impact Assessment (IA) & & & & & & Unknown \\
\hline 10 & Evaluation of Harvest Control Rules (HCR) for the Bay of Biscay Sole & & & & & & Not used \\
\hline 11 & French National Request on EU Landing Obligation & & & & & & Direct \\
\hline 12 & French National Request on impacts of TAC and quotas for the Bay of Biscay Fisheries & & & & & & Direct \\
\hline 13 & A participatory-based mapping of the Small Scale Fisheries (SSF) in the Basque fisheries & & & & & & Direct \\
\hline 14 & EU DGMARE DAMARA project in the Celtic demersal fisheries & & & & & & Indirect \\
\hline 15 & North Sea mixed fisheries research projects, ICES request and DGMARE direct contracts & & & & & & Direct \\
\hline 16 & EU project MAREFRAME- Strait of Sicily trawl fishery Case study & & & & & & Indirect \\
\hline 17 & EU project SOCIOEC - Bay of Biscay and Cetic sea Case studies & & & & & & Limited or indirect \\
\hline 18 & EU project MYFISH- Iberian Waters Case study & & & & & & Indirect \\
\hline 19 & EU DGMARE project on SSF sector's participation in decision-making & & & & & & Direct \\
\hline 20 & Celtic Sea Herring recovery plan and LTMP decision support & & & & & & Limited \\
\hline
\end{tabular}

scientists being included in project only to meet funding requirements.

Participants also highlighted the complexities in the roles of science in multi-level governance systems (Piattoni, 2009). For example, while in the EU there is central political decisionmaking on policies and (most) regulations, these are shaped through interactions at different levels and are often driven by contradictory goals of the stakeholders involved (Burns and Stöhr, 2011). In multi-level governance scenarios, the same scientists could "wear different hats" (Dankel et al., 2016) according to the level of decision-support considered (being for example knowledge integrator in research projects at EU level and policy advisor at national level as experienced by scientists involved in the EU in the SOCIOEC project (Case 17) as well as in supporting national requests on TAC options (Case 12). Wearing the same hat at national and European level is also possible (and generally observed with scientists being involved in national and EU decision-support processes). In these cases there may be confusion regarding their roles (particularly perceived by the fishing industry and national authorities) emerging from the fact that national and European objectives can diverge. For example, scientists can be advisers at the national level where authorities request scientific advice on potential socio-economic impacts of a particular policy or measure on their national fleet; yet, these same scientists may at the EU level (in STECF) also be involved in impact assessments of regional management plans with objectives set at a higher level of aggregation not necessarily addressing the specificity of national fleets. Wearing multiple hats can, however, also have benefits, by favouring information flow and uptake of science in decisionmaking in other cases. Nevertheless, this requires transparency on roles at different scales to avoid confusion, making a tool of participation or conflict of interest (Dankel et al., 2016). Participatory approaches described for example in Malvarosa et al. (2019) or Macher et al. (2018a) for impact assessment in fisheries propose processes for engagement and frameworks tending to clarify roles at each step. Discussions also highlighted the complementary need to reflect on research stances (i.e. strategic choices made by scientists) with regards to the nature of the knowledge, the methodology to produce it and its implementation and use as addressed in Hazard et al. (2020). This indeed determines the choices made at all steps in knowledge production and particularly in the implementation of transdisciplinary approaches.

\subsection{Main advantages/benefits of partnerships and interactions between scientists, decision-makers and industry}

From a multidisciplinary scientific perspective, five main advantages from collaborations (corroborating literature reviewed and SWOT) were identified by scientists involved in the case studies (Tab. 4-A and supplementary materials):

- Development of mutual trust. This was underlined in the Dutch Science-Industry Research Collaboration (Case 1), and the participatory small-scale fisheries mapping or the Celtic sea Herring case study (Case 20). In these cases trust building and maintenance was presented as one of the main advantages (and at the same time challenges) of the partnership. Increasing transparency and legitimacy of tools and scientific evidence were also pointed out as key basis for trust building in the Australian Partnership model (Case 2) and the French Partnership Working Group Project (Case 3).

- Improvement of data quality and availability, and validation of models. This was found to be an added value of partnerships mainly in the French industry project for self-sampling in Celtic Sea (Case 7), the Dutch ScienceIndustry Research Collaboration (Case 1) and the Irish Discardless Challenge Trials - Research Partnership (Case 6).

- Integration of knowledge, facilitation of information flow and structuring dialogue. In most of the projects, advantages were found in favouring information flow and knowledge sharing, incorporation of stakeholder preferences, identification of new research issues in common with stakeholders or improving co-construction and 
understanding between stakeholders (e.g. the Mareframe project (Case 16), MYFISH (Case 18), Dutch ScienceResearch Collaboration (Case 1) or the participatory based mapping of the small scale fisheries in the Basque fisheries, Case 13). Due to the nature of EBFM, advances towards implementation benefit from structured dialogues that make trade-offs between multiple objectives explicit and highlight the likely consequences of stakeholders' preferences (e.g. Mareframe project, Case 16)

- Increased salience, uptake and use of science to support decisions. This was underlined particularly in the Dutch Science-industry research collaboration (Case 1) or the EU DGMARE DAMARA project (Case 14). Interactions between scientists, decision-makers and industry and various forms of partnerships enable a more proactive approach to science in support of decision-support, increase engagement in the policy process, improve salience of science in decision-making or the uptake of science to inform management issues, and favour continuing use of science in decision-making.

- Improvement of governance, capacity and participation of stakeholders in the decision-support process. These kinds of benefits/advantages were particularly pointed out in the EU DGMARE project on SSF (Case 19) or the Mareframe project highlighting the benefits of inclusion of stakeholders' preferences (Case 16). It was also underlined in institutional advising process where partnerships between scientists and stakeholders increased capacity for stakeholders to propose scenarios or elicit options such as in the western waters management plan Impact assessment (Case 9) or the ICES Request for the Bay of Biscay sole (Case 10).

Table 4A summarizes the main kinds of benefits/ advantages from partnerships and participatory approaches observed in each case study and details are provided as supplementary materials.

\subsection{Impacts of partnerships and interactions and use of results in decision-making}

The workshop led to a classification of the use of results and impacts generated by Partnership Platforms, Institutional Scientific Advice processes and Contractual Projects in decision-making into five categories:

- Direct use, when results were thought to be taken into account to inform the decision;

- Limited use, when results provided were considered to be little considered in the decision-making process;

- Indirect use, when results could not be used directly to inform decision-making but have provided methods or social learning which can be used to inform decisionmaking in a second step;

- No use, when results were thought not to have contributed neither directly nor indirectly to the decision-making process;

- Unknown use, when scientists were not aware of the use made of their science in the decision-making process.

Table 4B presents the use of results for each project. Details and comments are provided as supplementary materials. It was found that in ten projects, results were used directly in the decision-making process. It was also found that direct use of results was associated with three factors. First, results are used directly when they were expected in the framework of an institutional procedure. An example is the Australian Partnership model (case 2), when results are directly used to set recommended biological catches or provide strategic scientific advice. Another example is a voluntary discards self-sampling scheme in the Dutch collaboration (case 1) which over time was integrated in the national data collection requirements (Steins et al., 2020). Second factor, the opening of a good window of opportunity contributes to direct results. For example, in the North Sea mixed fisheries case study (case 15) efficient information flow from science to decision-making was made possible between scientists working in research projects and involved in ICES advice groups like MIXFISH and decision-makers connected to research, which shaped the actual EU management plans for mixed fisheries based on Maximum Sustainable Yield (MSY). Finally, it was found that direct use of results is associated with a clearly defined role of scientists in the process.

Indirect use of results of partnerships generally takes place when projects focus on development of tools or methods to be used for decision-support, as is the case in EU funded projects (DAMARA, MareFrame, SOCIOEC, MYFISH, respectively cases 14, 16, 17, 18 in Tab. 4B) or in the Partnership Bioeconomic WG project (case 3). Outputs of these projects fed into a current need and supported the advice and the development of management plans in the area concerned. These projects also reported an indirect impact in terms of capacity building for stakeholders and decision-makers to be used in decision-making; scientists also benefit from the learning process, gaining salience and relevance of the research output. Therefore, they have resulted in a wider and better understanding by all partners of potential responses to specific challenges and/or improve capability to design feasible responses to a given problem that is difficult to assess. This two-way capacity building (Steins et al., 2020) was also observed in projects were results were used directly, such as the Dutch science-industry collaboration (Case 1).

No use occurs in two projects for different reasons. In the Irish Discardless Challenge Trials (Case 6), there were no formal links to decision-making in this partnership between scientists and stakeholders. In the case of Bay of Biscay Sole HCR evaluation (Case 10), the management plan under development was finally not implemented and replaced by multispecies management plans under the reform of the CFP.

Use of the results was limited or unknown in other cases. This typically occurred due to poor information and feedback on the real needs and use made by decision-makers of the scientific information in the final decisions (cases 9, 17, 20).

\subsection{Difficulties towards EBFM encountered in collaborations and decision-processes}

The workshop also discussed difficulties encountered in partnerships and decision-support as listed in the templates and recommendations to address them. They confirm some of the issues highlighted in the SWOT exercises (Macher et al., 2018 b). Results are detailed in the supplementary materials.

A first difficulty is the mismatch between the pace of research and the short-term political agenda. This issue was particularly noticed in the Dutch SIRC (Case 1) and the French Partnership project (Case 3). It was also mentioned in relation 
to a larger issue regarding the risk of inconsistency between science and managerial needs highlighted in the AZTI Spanish Secretary project (Case 5).

Second, several projects experienced a lack of stakeholder engagement in some steps of the processes or the lack of coconstruction. This was highlighted in particular in institutional decision-support processes where the timelines do not enable proper engagement. An example is case study 9 where the political agenda for impact assessment of management plans led to engaging stakeholders as merely observers. Lack of engagement was not limited to stakeholders. In addition, decision-makers and managers were sometimes insufficiently included in projects and collaborations, as pointed out in Section 4.1 (in case studies 16-MAREFRAME project or 20-Celtic Sea Herring fishery for example). This was felt as a major obstacle affecting salience of research and thus efficient EBFM.

Fears from stakeholders that involvement in partnerships would eventually lead to results being used against them, is a third issue encountered in some case studies. This calls for more transparency of the process and objectives. This point relates to a fourth difficulty: the lack of clarification in roles and objectives of the collaborations. This issue, and recommendations, has been addressed in in Section 4.2.

Fifth, the lack of resources and skills (human capacity and capabilities) to facilitate engagement and knowledge integration was considered to be a difficulty. While almost all the case studies involved scientists from the natural and social sciences, there was large variation in the social sciences fields engaged in the collaboration (see Tab. 1). In most of the case studies, economists and biologists were engaged in participatory impact assessment processes based on modelling approaches and evaluations, while involvement of other social sciences trained in qualitative methods was more limited or absent. Involvement of external facilitators to support engagement processes was also not widespread.

Finally, lack of institutional and financial support were a difficulty highlighted by most of the participants. This was considered a major issue preventing the development of long term collaborations and innovative platforms of transdisciplinarity where roles and processes would be clarified towards implementation of an efficient EBFM. Funding issues were also addressed with regards to the late engagement of stakeholders in research observed in many cases. This could be improved by pre-research funding dedicated to early engagement of stakeholders in the project definition.

As part of the general discussion to the workshop, the need for cross-study comparison and the development of community of practices (Wenger, 2000) was recommended together with an increasing engagement of social scientists outside economics in processes to lead and facilitate reflexive approach (underlined by Ely et al., 2020 as loop learning) towards transdisciplinarity and EBFM.

\section{Recommendations for transdisciplinary decision-support towards EFBM}

The workshop results indicate that science-stakeholdermanagers partnerships for decision-support in fisheries can play an essential role in the transition to EBFM by: (a) contributing to the integration of academic and practitioner's knowledge, (b) encouraging scientists from different disciplines in working together for decisionsupport (c) building trust (d) developing capacity for engagement in science and policy, (e) facilitating information flow from science to decision-making and (f) increasing salience of science. At present, existing interactions between scientists, stakeholders and managers, with their multiple objectives and impacts on processes towards EBFM are based on "learning by doing" approaches for stakeholders' engagement. Participatory approaches as well as the public funding requirements to engage with stakeholders and support decision-making may appear at odds with how fisheries stakeholders, scientists and managers operate. Furthermore, there is limited hindsight and analysis of the benefits and impacts of stakeholder partnerships and of the roles played by scientists in this process. An effective EBFM implementation requires mutual learning and drawing lessons on which interactions may improve transdisciplinarity in decision-support, and how these can be operationalized (Ely et al., 2020). This requires collaborations between various scientific disciplines, from social and natural sciences, involved in impact assessments (i.e. economics, sociology or political sciences; biology and ecology) as well as in the policy process to support decision.

The analysis of 20 concrete case studies of Partnership Platforms, Institutional Decision-support Frameworks and Contractual Projects in fisheries developed by SciPaDe, highlights eight recommendations in relation to the transformative role of science and scientists and the role of partnership platforms in the implementation of EBFM.

\subsection{Explore how transdisciplinarity and diversity of interactions can help effective EBFM}

First, there is a need to explore how and to what extent the different kinds and nature of the interactions (stakeholders involved, formalized or not formalized, permanent or opportunistically linked to a project) may lead to a better performance in decision-support based on transdisciplinary and co-produced research (West et al., 2019). Better performance can be measured by looking at improved salience of science. It is expected that this will contribute to a more effective (implementation of) EBFM. Effective EBFM covers complex issues characterized by contested priorities, differing scale dependent values, lack of consensus about implementation and outcomes. Therefore, it is necessary to understand the diversity of interactions: 1) does this result from interactions limited to a project or to an expertise without long-term perspectives or framework to pursue collaboration? 2) does this exist because forms of interactions and parties to be involved are too specific to scales and context and that lack of formalization gives the flexibility and adaptability needed?, or 3) does this respond to functional and contextual factors? For instance, informal interactions are better suited in terms of adaptability and flexibility than formalized processes. Likewise, scale and context features condition the attributes of the interaction as well as the profile of those involved in it. 


\subsection{Improve engagement of decision-makers and managers and diversity of science-policy interfaces}

Second, there is a need to improve engagement of decisionmakers in decision-support processes with scientists and to increase and diversify interactions between scientists and authorities. These interactions are often limited to unidirectional and sequential interactions driven by requests from the administration addressed by scientists. Improving interactions between scientists and managers and linking science and action will contribute to the co-construction of research questions and may increase the saliency and uptake of science (West et al., 2019). It would also reduce misunderstanding of what science can or cannot deliver, preventing a good up-take of science (as illustrated in Shuterland et al., 2013). Likewise scientists can learn to better understand decision-makers' needs and constraints (as listed by Tyler, 2013 as an answer to Shuterland et al., 2013). Favouring mobility of scientists in administrations or decision-making bodies could help in better scoping the needs and expectations from science and decisionmaking. Training courses specifically dedicated to managers would also contribute to capacity building and enhance up-take of results from science.

\subsection{Identify and track information flow from production to use}

Third, results re-emphasise the conclusions by Soomai (2017) on the importance of identifying and tracking the information flow, and the use of science for decision to assess direct and indirect impacts. While SciPaDe reviewed use and uptake of the results in the different case studies, it was not possible to assess their real impacts on decision-making. Evaluations of the effectiveness of the approaches are not easy due to limited track on the uptake of science, poor feedback from policy to science, and scientists' limited understanding of the needs from fisheries managers. Developing and implementing methods for measuring the flow and uptake of science, including the attributes of the information flow and who is in charge of it at different points of the process would be useful. This would enable assessment of the efficiency of the different forms of interactions and roles of science in improving salience and uptake of science and implementing EBFM through better participation in the decision-support and decision-making process. It would also facilitate the identification of best practices/conditions for a good information flow (leadership, relationship, etc.).

\subsection{Reconcile expectations, pace of science and appropriate complexity}

Fourth, management of expectations on the pace of science in relation to its readiness for use should be an integral aspect from the outset of decision-support partnerships. One of the main misunderstandings existing between scientists, stakeholders and decision-makers concerns the pace of science. Science is seen as too slow for policy-makers and stakeholders who need the provision of scientific advice in minimal time at minimal costs (Steins et al., 2020; Mangi et al., 2018). That need for quicker answers can threaten the quality of the scientific advice provided, as it tends to promote simpler approaches. This opens a range of research questions on the ability of simpler approaches to highlight trade-offs, the added value of more complex approaches and the possible use of a combination of both approaches depending on issues at hand. For example, Management Strategy Evaluation frameworks are complex but tend to enhance the capacity to provide integrated assessment of management trade-offs to support decision-making, including for EFBM (Mackinson and Middleton, 2018). Research conducted for several years on Models of Intermediate Complexity for Ecosystem assessment (e.g. Plaganyi et al., 2014) proposes operational, less complex alternatives to full ecosystem-models in EBFM.

\subsection{Clarify roles of all parties in the transdisciplinary approach (including role(s) of scientists)}

Fifth, the roles of all parties involved in the partnerships, and those of the scientists in particular, should be made explicit from the outset. The findings highlight the new role and place of science in facilitating transdisciplinary approaches to improve the decision-support process and the implementation of EBFM. Being a scientist working in decision-support today has, as it were, become a new job with associated challenges: mono-disciplinary pure scientists are increasingly expected to work as transdisciplinary integrators of (co-created) knowledge in support of decision-making. This is not to say that all pure scientists should become integrators; both are needed. However, there is a need for clarification of the roles held by scientists in the process of decision-support and decision; Dankel et al. (2016) address it in their analysis of the multiple roles of fishery scientists in the ICES community and possible consequences of wearing different "hats". Lessons learnt from experiences in twenty case studies capture the heterogeneity of roles held by scientists according to projects, or even in the same project and according to the nature of the interactions and the partnership. This can create confusion for the partners (stakeholders or managers). They may for example expect a pure producer of knowledge while the scientist is actually involved to propose new approaches for knowledge broking. A clarification of the roles of each partner using an appropriate typology and joint reflection on this throughout the process will assist improving efficiency of partnership platforms and prevent misunderstandings.

\subsection{Build capacities, practices and places for transdisciplinarity}

Sixth, also related to the previous point, capacity building to enable working in transdisciplinary setting is key. Having new roles also place new demands on scientists, which raises questions in relation to their capacity and capability to adapt to these changed roles. Lang et al. (2012) or Said et al. (2019) detail the principles of a transdisciplinary approach including the open-mindedness in knowledge integration and personal traits of the partners to foster transdisciplinary learning and the required process of communication and facilitation of problem and solution identification. Facilitating and organizing 
interactions between science and society, and building and developing transdisciplinary approaches are becoming increasingly important issues with consequences for scientists as well as stakeholders. SciPaDe's findings highlight that transdisciplinary approaches should be encouraged to build capacity, develop common practices and bring clarity to the roles played in decision-support framework context. It underlines the need to develop platforms enabling the transdisciplinary approach of the fisheries social-ecological system to be managed (Chuenpagdee and Jentoft, 2019; Tengö et al., 2014). Cvitanovic et al. (2015) suggest novel approaches to knowledge exchange associating knowledge brokers to favour co-production of knowledge and the emergence of dedicated boundary organisations. This raises questions on new competencies and tools in research to assist in transdisciplinary integration, but can also emphasize the need to develop new profiles and professionals to support scientists in this task. In this context, the social sciences have much to offer. Next to the provision of social data and information, social sciences also contribute to: (i) the analyses of practices of and between scientists and stakeholders in projects and decision-making processes thereby clarifying the roles, (ii) the gathering of data from stakeholders through interviews, focused groups, mapping, and in knowledge co-creation (for instance the gathering and use of fishers knowledge in the understanding of the socio-ecosystems' dynamics and possible futures (Stephenson et al., 2016), (iii) training natural scientists in methods to gather and analyse systematic information from stakeholders and provide feedback, e.g. the GAP2-project (Holm et al. (Ed), 2020), and (iv) reflexivity on methods, tools, and the different roles of and interactions between the various participants in collaborations for decision-support and what this means for outcomes. Social science thus provides methodological development for the integration of stakeholders' knowledge and how to value this knowledge in the scientific process, and contributes to enlightening the roles of scientists in partnerships and in diverse interactions with stakeholders and managers.

\subsection{Revisite current funding models for a meaningful engagement}

Seventh, to allow for active integration of stakeholders' in research, current funding models need to be revisited. Meaningful engagement of stakeholders in science for decision-support means that they are involved from the inception, including the development of research questions and methodology (Steins et al., 2020; Johnson and Van Densen, 2007; Holm et al., 2020). Increasingly researchfunding programmes focusing on societal impacts demand engagement of stakeholders. However, often research proposals do not include active pre-research that involves stakeholders to articulate their specific questions. As a result, research proposals in support of decision-support are commonly developed with little or no involvement of stakeholders, and as such, stakeholder engagement often becomes an add-on instead of an integral part of the entire project cycle. Finance for pre-research and engagement should be considered.

\subsection{Develop reflexive approaches, networks and cross-comparison for mutual learning and efficient transdisciplinarity}

Finally, the lessons learnt from the case studies presented should be further explored through systematic cross-study and cross-scale comparisons and practice-based approaches favouring mutual learning (Ely et al., 2020; West et al., 2019; Österblom et al., 2020). Assessment of advantages and benefits of interactions between scientists and stakeholders (including fishing industry and managers) in SciPaDe reflects only the scientific point of view. Including stakeholders' and decision-makers' views was outside the scope of the workshop, but offers a perspective for further work. Involving decision-makers and stakeholders and, gathering and discussing their perceptions of the advantages of those interactions and partnership is necessary to better understand the salience, legitimacy and credibility of science. The methodology, including the common template, used by SciPaDe may assist in these efforts. Further in-depth cross analysis based on broadening scope to include all stakeholders in such reviews will provide further recommendation for actionable knowledge for decision-support processes in fisheries. This will help in designing the attributes of efficient transdisciplinary platforms allowing interactions between stakeholders and scientists, and links with the decision-making process at a level that is useful. There is thus a need to build up networks to review, develop and institutionalize transdisciplinary platforms and to manage and develop a community of practice (Wenger, 2000) reflecting on research stances towards efficient transdisciplinarity (Hazard et al., 2019; Ely et al., 2020) and taking advantage of collective experience (Österblom et al., 2020).

\section{Conclusions}

Science/stakeholder/managers partnerships for decisionsupport in fisheries can play an essential role in knowledge integration towards EBFM. The development of transdisciplinary approaches is key to facilitate the functioning of such platforms in co-creating knowledge for decision-support. The SciPade workshop resulted in eight recommendations to foster this process. Analysis of the kind and nature of interactions between participants and joint reflection of findings will contribute to increased performance of decision-support platforms and co-produced knowledge. In the latter, engagement of managers should be encouraged. Tracking the flow and uptake of science in decision-making is another important aspect. At the same time, management of expectations on the pace of science in relation to its readiness for use should be addressed from the very beginning. Transparent definitions and clarifications of the roles of the participants and "hats" scientists, stakeholders and decision-makers are wearing, are of key importance. These should be based on typologies grounded on experience and not on theory. To assist scientists with transitioning to new roles as part of adopting transdisciplinary approaches, capacity building is essential. This can be done through training, but also by building networks or a community of practice where experiences experience and practices for EFBM decision-support can be 
shared and reviewed. In this process, there is a particular need to increase the role of social sciences to cooperate with natural scientists and policy-makers in organizing active involvement of stakeholders in decision-support process, including joint problem definition, bringing stakeholders' knowledge to the table, making different perceptions visible and highlighting trade-offs. To organize active integration of stakeholders' needs and knowledge in EFBM decision-support research, current funding models need to be revisited. Further exploration of conditions for effective platforms through systematic analyses of concrete cases is required.

Attention for reflexivity based on own and others' experiences should help designing the next generation transdisciplinary platforms and providing actionable knowledge for transitioning towards EBFM. Future research and innovation framework programmes into sustainable fisheries and other ocean uses should explicitly include mechanisms to foster transdisciplinary approaches and the development of best practices.

\section{Supplementary Material}

Supplementary file supplied by the authors.

The Supplementary Material is available at https://www.alr-journal.org/10.1051/alr/2021010/olm.

Acknowledgements. The SciPaDe workshop was supported by a grant from the French National Research Agency under the programmes "Investissements d'Avenir" ISblue (ANR-17EURE-0015) (https://www.isblue.fr) and LabexMER (ANR10-LABX-19) (https://www.labexmer.eu/fr). This financial support is gratefully acknowledged. Findings of SciPaDe were presented at the ICES Annual Science Conference $\left(2018^{3}\right)$, at the Future Oceans ${ }_{2}$ Integrated Marine Biosphere Research project (IMBeR) Open Science Conference $\left(2019^{4}\right)$ and were also used as input for discussions at the Global Ocean Social Sciences event (GLOSS, 20195). Authors would like to thank participants to these events for their feedbacks on previous versions of this work and the anonymous reviewers for their helpful comments.

Glossary- derived from Tress et al., 2004.

Multi-disciplinarity: refers to research efforts of different disciplines carried out towards a shared goal but with multiple disciplinary objectives and without integration between the disciplines.

Inter-disciplinarity: refers to research efforts crossing boundaries to integrate different academic disciplines and create new knowledge and theory towards a common goal.

Trans-disciplinarity: refers to integration of academic and non-academic knowledge (local and professional knowledge from non-academic participants to the research) to create new knowledge and theory towards a common goal.

\footnotetext{
$\overline{{ }^{3} \text { http://ices.dk/news-and-events/asc/ASC2018 }}$

${ }^{4}$ http://www.imber.info/en/events/osc-imber-open-science-confer ence/osc-2019/2019-imber-open-science-conference

${ }^{5}$ http://ocean-univ.org/gloss
}

\section{References}

Ballesteros M, Chapela R, Ramírez-Monsalve P, Raakjaer J, Hegland TJ, Nielsen KN, Laksa U, Degnbol P. 2018. Do not shoot the messenger: ICES advice for an ecosystem approach to fisheries management in the European Union. ICES J Mar Sci 75: 519-530.

Barreteau O, Bots PWG, Daniell KA. 2010. A framework for clarifying "Participation" in participatory research to prevent its rejection for the wrong reason. Ecol Soc 15: 1.

Berghöfer A, Wittmer H, Rauschmayer F. 2008. Stakeholder participation in ecosystem-based approaches to fisheries management: a synthesis from European research projects. Marine Policy 32: 243-253.

Berkes F, Folke C. (Eds.). 2000. Linking social and ecological systems. Management practices and social mechanisms for building resilience, Cambridge University Press, Cambridge.

Biggs SD. 1989. Resource-poor farmer participation in research: a synthesis of experiences from nine national agricultural research systems, OFCOR - Comparative Study, INSAT, Hague. p. 54.

Blythe J, Nash KL, Yates JS, Cumming GS. 2017. Feedbacks as a bridging concept for advancing transdisciplinary sustainability research. Curr Opin Environ Sustainability 26-27: 114-119.

Burns TR, Stöhr C. 2011. Power, knowledge, and conflict in the shaping of commons governance. The case of EU Baltic fisheries. Int J Commons 5: 233-258.

Chuenpagdee R, Jentoft S. (Eds.). 2019. Transdisciplinarity for smallscale fisheries Governance. Ananlysis and Practice. MARE publication series. Vol. 21. Springer Ed. p. 479.

Cvitanovic C, Hobday AJ, van Kerkhoff L, Wilson SK, Dobbs K, Marshall NA. 2015. Improving knowledge exchange among scientists and decision-makers to facilitate the adaptive governance of marine resources: a review of knowledge and research needs. Ocean Coast Manage 112: 25-35.

Cvitanovic C, Howden M, Colvin RM, Norström A, Meadow AM, Addison PFE. 2019. Maximising the benefits of participatory climate adaptation research by understanding and managing the associated challenges and risks. Environ Sci Policy 94: 20-31.

Cvitanovic C, McDonald J, Hobday AJ. 2016. From science to action: principles for undertaking environmental research that enables knowledge exchange and evidence-based decision-making. J Environ Manage 183: 864-874.

Dankel DJ, Stange K, Nielsen KN. 2016. What hat are you wearing? On the multiple roles of fishery scientists in the ICES community. ICES J Mar Sci 73: 209-216.

Dickey-Collas M, Ballesteros M. 2019. Swinging back? Science ethos and stakeholders'engagement in ICES advisory processes. ICES Newsletter, September. Available at http://ices.dk/newsand-events/news-archive/news/Pages/Science-ethos-and-stake holders $\%$ E2\%80\%99-engagement-in-ICES-advisory-processes. aspx.

Eigenbrode SD, O'rourke M, Wulfhorst JD, Althoff DM, Goldberg CS, Merrill K, Morse W, Nielsen-Pincus M, Stephens J, Winowiecki L, Bosque-Pérez NA. 2007. Employing philosophical dialogue in collaborative science. BioScience 57: 55-64.

Ely A, Marin A, Charli-Joseph L, Abrol D, Apgar M, Atela J, Ayre B, Byrne R, Choudhary BK, Chengo V, Cremaschi A, Davis R, Desai P, Eakin H, Kushwaha P, Marshall F, Mbeva K, Ndege N, Ochieng C, Ockwell D, Olsson P, Oxley N, Pereira L, Priya R, Tigabu A, Van Zwanenberg P, Yang L. 2020. Structured collaboration across a transformative knowledge network - learning across disciplines, cultures and contexts? Sustainability 12: 2499.

European Commission. 2009. Impact assessement Guidelines. SEC (2009) 92, 50 p. http://ec.europa.eu/smart-regulation/impact/ commission_guidelines/docs/iag_2009_en.pdf 
Funtowicz SO, Ravetz JR. 1993. Science for the postnormal age. Futures 25: 739-755.

Gray TS. (Ed.), Participation in fisheries governance. Springer, Dordrecht, 2005.

Gray TS, Hatchard J. 2008. A complicated relationship: stakeholder participation and the ecosystem-based approach to fisheries management. Mar Policy 32: 158-168.

Hazard L, Cerf M, Lamine C, Magda D, Steyaert P. 2020. A tool for reflecting on research stances to support sustainability transitions. Nat Sustainability 3: 89-95.

Holm P, Hadjimichael M, Linke S, Mackinson S. (Eds.), Collaborative Research in Fisheries, Co-creating Knowledge for Fisheries Governance in Europe, MARE Publication Series 22. Springer, Cham, 2020.

Hoppe R. 2005. Rethinking the science-policy nexus: from knowledge utilization and science technology studies to types of boundary arrangements. Poiesis Praxis 3: 119-215.

Hoppe R. 2009. Scientific advice and public policy: expert advisers' and policymakers' discourses on boundary work. Poiesis Praxis 6: 235-263.

ICES, Report of the Workshop on translating science into advice (WKSCIENCE2ADVICE). ICES Headquarters, Denmark, 2018. ICES CM 2018/IEASG:14. 26 p. http://ices.dk/sites/pub/Publica tion\%20Reports/Expert\%20Group\%20Report/IEASG/2018/ WKSCIENCE2ADVICE/WKSCIENCE2ADVICE\%202018.pdf

ICES, Workshop on Science with Industry Initiatives (WKSCINDI). ICES Scientific Reports, vol. 68, Nr. 1. International Council for the Exploration of the Sea, Copenhagen, 2019.

Jentoft S, Chuenpagdee R. 2009. Fisheries and coastal governance as a wicked problem. Mar Policy 33: 553-560.

Johnson TR, Van Densen WLT. 2007. Benefits and organization of cooperative research for fisheries management. ICES J Mar Sci 64: 834-840.

Kempf A, Mumford J, Levontin P, Leach A, Hoff A, Hamon KG, Bartelings H, Vinther M, Staebler M, Poos JJ, Smout S, Frost H, van den Burg S, Ulrich C, Rindorf A. 2016. The MSY concept in a multi-objective fisheries environment - Lessons from the North Sea. Mar Policy 69: 146-158.

Kraan M, Hendriksen A, van Hoof L, van Leeuwen J, Jouanneau C. 2014. How to dance? The tango of stakeholder involvement in marine governance research. Mar Policy 50: 347-352.

Lang DJ, Wiek A, Bergmann M, Stauffacher M, Martens P, Moll P, Swilling M, Thomas CJ. 2012.Transdisciplinary research insustainability science: practice, principles, and challenges. Sustainability Sci 7: 25-43.

Leslie HM, McLeod KL. 2007. Confronting the challenges of implementing marine ecosystem-based management. Front Ecol Environ 5: 540-548.

Macher C, Bailly D, Ballesteros M, Bertignac M, Colloca F, Fitzpatrick M, Frangoudes K, Garcia D, Kraan M, Little R, Mardle S, Murillas A, Pawlowski L, Philippe M, Prellezo R, Sabatella E, Steins N, Thebaud O, Ulrich C. 2018b. Science, partnership and decision support processes in fisheries: sharing experiences and practices and identifying Lessons learnt from an interdisciplinary perspective. Workshop Report, https://archimer.ifremer.fr/doc/ 00463/57452/

Macher C, Bertignac M, Guyader O, Frangoudes K, Fresard M, Le Grand C, Merzereaud M, Thebaud O. 2018a. The role of technical protocols and partnership engagement in developing a decisionsupport framework for fisheries management. J Environ Manage 223: 503-516.

Mackinson S, Middleton D. 2018. Evolving the ecosystem approach in European fisheries: transferable lessons from New Zealand's experience in strengthening stakeholder involvement. Mar Policy 90: 194-202.

Mackinson S, Wilson DC, Galiay P, Deas B. 2011. Engaging stakeholders in fisheries and marine research. Mar Policy 35: 18-24.

Malvarosa L, Murillas A, Lehuta S, Nielsen JR, Macher C, Goti L, Motova A, Doering R, Haraldson G, Accadia P, Hamon K, Bastardie F, Maravelias CD, Mardle S, Thøgersen T. 2019. Sustainability Impact Assessment (SIA) in fisheries: implementation in EU fishing regions. Mar Policy 101: 63-79.

Mangi S, Kupschus S, Mackinson S, Rodmell D, Lee A, Bourke E, Rossiter T, Masters J, Hetherington S, Catchpole T, Righton D. 2018. Progress in designing and delivering effective fishing industry-science data collection in the UK. Fish Fisheries 19: 622-642.

Mason JG, Rudd MA, Crowder LB. 2017. Ocean research priorities: similarities and differences among scientists, policymakers, and fishermen in the United States. Bioscience 67: 418-428.

Mauser W, Klepper G, Rice M, Schmalzbauer BS, Hackmann H, Leemans R, Moore H. 2013. Transdisciplinary global change research: the co-creation of knowledge for sustainability. Curr Opin Environ Sustainability 5: 420-431.

McLeod KL, Lubchenco J, Palumbi SR, Rosenberg AA. 2005. Scientific Consensus Statement on Marine Ecosystem-Based Management. Signed by 221 academic scientists and policy experts with relevant expertise and published by the Communication Partnership for Science and the Sea. p. 21.

Merzereaud M, Biais G, Lissardy M, Bertignac M, Biseau A. 2013. Evaluation of proposed harvest control rules for Bay of Biscay sole. CIEM, Ref. ICES CM 2013/ACOM:75, 18 p. https:// archimer.ifremer.fr/doc/00162/27283/

OECD, OECD Best Practice Principles on Stakeholder Engagement in Regulatory Policy. OECD, Paris, 2016.

Österblom H, Cvitanovic C, van Putten I, Addison P, Blasiak R, jouffray J-B., Bebbington J, Hall J, Ison S, Le Bris A, Mynott S, Reid D, Sugimoto A. 2020. Science-industry collaboration: sideways or highways to ocean sustainability. One Earth 3: 24.

Piattoni S. 2009. Multi-level governance: a historical and conceptual analysis. J Eur Integr 31: 163-180.

Pielke RA Jr, The honest broker: making sense of science in policy and politics, Cambridge University Press, Cambridge, UK, 2007.

Pikitch EK, Santora C, Babcock EA, Bakun A, Bonfil R, Conover DO, Dayton P, Doukakis P, Fluharty D, Heneman B, Houde ED, Link J, Livingston PA, Mangel M, McAllister MK, Pope J, Sainsbury KJ. 2004. Ecosystem-based fishery management. Science 305: 346-347.

Plaganyi EE, Punt AE, Hillary R, Morello EB, Thebaud O, Hutton T, Pillans RD, Thorson JT, Fulton EA, Smith ADM, Smith F, Bayliss P, Haywood M, Lyne V, Rothlisberg PC. 2014. Multispecies fisheries management and conservation: tactical applications using models of intermediate complexity. Fish Fisheries 15: $1-22$.

Popa F, Guillermin M, Dedeurwaerdere TA. 2015. A pragmatist approach to transdisciplinarity in sustainability research: from complex systems theory to reflexive science. Futures 65: 45-56.

Probst K, Hagmann J, Fernandez ME, Ashby J, Understanding Participatory Research in the Context of Natural Resource Management: Paradigms, Approaches and Typologies, Agren Network paper $\mathrm{N}^{\circ} 130$. Agricultural Research \& Extension Network, 2003, p. 19.

Ramirez-Monsalve P, Raakjær J, Nielsen KN, Santiago JL, Ballesteros M, Laksa U, Degnbol P. 2016. Ecosystem Approach to Fisheries Management (EAFM) in the EU-current science- 
policy-society interfaces and emerging requirements. Mar Policy 66: 83-92.

Reed MS. 2008. Stakeholder participation for environmental management: a literature review. Biol Conserv 141: 2417-2431.

Reed MS, Stringer LC, Fazey I, Evely AC, Kruijsen JHJ. 2014. Five principles for the practice of knowledge exchange in environmental management. J Environ Manage 146: 337-345.

Rindorf A, Dichmont CM, Levin PS, Mace P, Pascoe S, Prellezo R, Punt AE, Reid DG, Stephenson R, Ulrich C, Vinther M, Clausen LW. 2017a. Food for thought: pretty good multispecies yield. ICES J Mar Sci 74: 475-486.

Rindorf A, Mumford J, Baranowski P, Clausen LW, García D, Hintzen NT, Kempf A, Leach A, Levotntin P, Mace P, Mackinson S, Maravelias C, Prellezo R, Quetglas A, Tserpes G, Voss R, Reid D. 2017b. Moving beyond the MSY concept to reflect multidimensional fisheries management objectives. Mar Policy 85: 33-41.

Robinson P, Genskow K, Shaw B, Shepard R. 2012. Barriers and opportunities for integrating social science into natural resource management: lessons from National Estuarine Research Reserves. Environ Manage 50: 998-1011.

Röckmann C, Kraan M, Goldborough D, Hoof LV. 2018. Stakeholder participation in marine management: the importance of transparency and rules for participation, in: P. Levin, M. Poe (Eds.), Conservation in the Anthropocene Ocean.

Röckmann C, Ulrich C, Dreyer M, Bell E, Borodzicz E, Haapasaari P, Hauge KH, Howell D, Mäntyniemi S, Miller D, Tserpes G, Pastoors M. 2012. The added value of participatory modelling in fisheries management - what has been learnt? Mar Policy 36: 1072-1085.

Röckmann C, van Leeuwen J, Goldsborough D, Kraan M, Piet G. 2015. The interaction triangle as a tool for understanding stakeholder interactions in marine ecosystem based management. Mar Policy 52: 155-162.

Said A, Chuenpagdee R, Aguilar-Perera A, Arce-Ibarra M, Gurung TB, Bishop B, Leopold M, Marquez Pérez AI, Gomes de Mattos SM, Pierce GJ, Nayak PK, Jentoft S. The Principles of transdisciplinary research in small scale fisheries, in: $R$. Chuenpagdee, S. Jentoft (Eds.), MARE Publication Series, Vol. 21. Springer, Cham, 2019, pp. 411-431.

Sampedro P, Prellezo R, García D, Da-Rocha J-M., Cerviño S, Torralba J, Touza J, García-Cutrín J, Gutiérrez MJ. 2017. To shape or to be shaped: engaging stakeholders in fishery management advice. ICES J Mar Sci 74: 487-498.

Shuterland WJ, Spiegelhalter D, Burgman MA. 2013. Twenty tips for interpreting scientific claims. Nature 503: 335-337.

Smith ADM, Sainsbury KJ, Stevens RA. 1999. Implementing effective fisheries-management systems - management strategy evaluation and the Australian partnership approach. ICES J Mar Sci 56: 967-979.
Smith DC, Smith ADM, Punt AE. 2001. Approach and process for stock assessment in the South East Fishery, Australia: a perspective. Mar Freshw Res 52: 671-681.

Soomai SS. 2017. Understanding the science-policy interface: case studies on the role of information in fisheries management. Environ Sci Policy 72: 65-75.

Spruijt P, Knol AB, Vasileiadou E, Devilee J, Lebret E, Petersen AC. 2014. Roles of scientists as policy advisers on complex issues: a literature review. Environ Sci Policy 40: 16-25.

Steins NA, Kraan ML, van der Reijden KJ, Quirijns FJ, van Broekhoven W, Poos JJ. 2020. Integrating collaborative research in marine science: recommendations from an evaluation of evolving science-industry partnerships in Dutch demersal fisheries. Fish Fish 21: 146-161.

Stephenson RL, Paul S, Pastoors MA, Kraan M, Holm P, Wiber M, Mackinson S, Dankel DJ, Brooks K, Benson A. 2016. Integrating fishers' knowledge research in science and management. ICES J Mar Sci 73: 1459-1465.

Tengö M, Brondizio ES, Elmqvist T, Malmer P, Spierenburg M. 2014. Connecting diverse knowledge systems for enhanced ecosystem governance: the multiple evidence base approach. $A M B I O A \mathrm{~J}$ Human Environ 43: 579-591.

Thebaud O, Innes J, Doyen L, Lample M, Macher C, Mahevas S, Mullon C, Planque B, Quaas M, Smith T, Vermard Y. 2014. Building ecological-economic models and scenarios of marine resource systems: workshop report. Mar Policy 43: 382-386.

Thompson SA, Stephenson RL, Rose GA, Paul SD. 2019. Collaborative fisheries research: the Canadian Fisheries Research Network experience. Can J Fish Aquat Sci 76: 671-681.

Tress G, Tress B, Fry G. 2004. Clarifying integrative research concepts in landscape ecology. Landsc Ecol 20: 479-493.

Turnhout E, Stuiver M, Klostermann J, Harms B, Leeuwis C. 2013. New roles of science in society: different repertoires of knowledge brokering. Sci Public Policy 40: 354-365.

Tyler C. 2013. Top 20 things scientists need to know about policymaking. The Guardian, 2013.

Vielmini I, Perry AL, Cornax MJ. 2017. Untying the Mediterranean Gordian Knot: a twenty first century challenge for Fisheries Management. Front Mar Sci 4: 195.

Voinov A, Bousquet F. 2010. Modelling with stakeholders. Environ Modell Software 25: 1268-1281.

Wenger E. 2000. Communities of practice and social learning systems. Organization 7: 225-246.

West S, van Kerkhoff L, Wagenaar H. 2019. Beyond "linking knowledge and action": towards a practice-based approach to transdisciplinary sustainability interventions. Policy Studies 40: 534-555.

Wilson DC. The Paradoxes of Transparency: Science and the Ecosystem Approach to Fisheries Management in Europe. MARE Publication. Amsterdam University Press, Amsterdam, 2009.

Cite this article as: Macher C, Steins NA, Ballesteros M, Kraan M, Frangoudes K, Bailly D, Bertignac M, Colloca F, Fitzpatrick M, Garcia D, Little R, Mardle S, Murillas A, Pawlowski L, Philippe M, Prellezo R, Sabatella E, Thébaud O, Ulrich C. 2021. Towards transdisciplinary decision-support processes in fisheries: experiences and recommendations from a multidisciplinary collective of researchers. Aquat. Living Resour. 34: 13 


\section{Appendix A: SciPaDe template used for comparison of case studies}

Case study

Column to be filled out by participant

Decision-support process

Context (political and institutional context, existing demand, spatial scale....)

Framework of the decision-support (project(s) contracted or not, expertise?

regulatory obligation of Impact assessment, informal framework ...)

Deliverables expected/provided

Links with decision-making process

Your role and expertise in the decision-support process

Partnership science-decision-makers, science-stakeholders

With who? scale and partners

How? Nature of the partnership (kind of relationships, leadership, continuity or opportunism, partnership agreements? Or contract? Or informal partnership)

Why? Objectives of the partnership?

Kinds of collaboration (consultation, information sharing, co-construction) and methods used

\section{Lessons learnt}

Use of the results for decision-making

Benefits of the partnership

Difficulties, constraints or counterparties

Perspectives and opportunities

Recommendations to improve decision-support and the use of results

Recommendations to improve partnership approaches

Comments 


\section{Appendix B: Pirate Ship playful poster to conduct the SWOT analyses - source - Worklab}

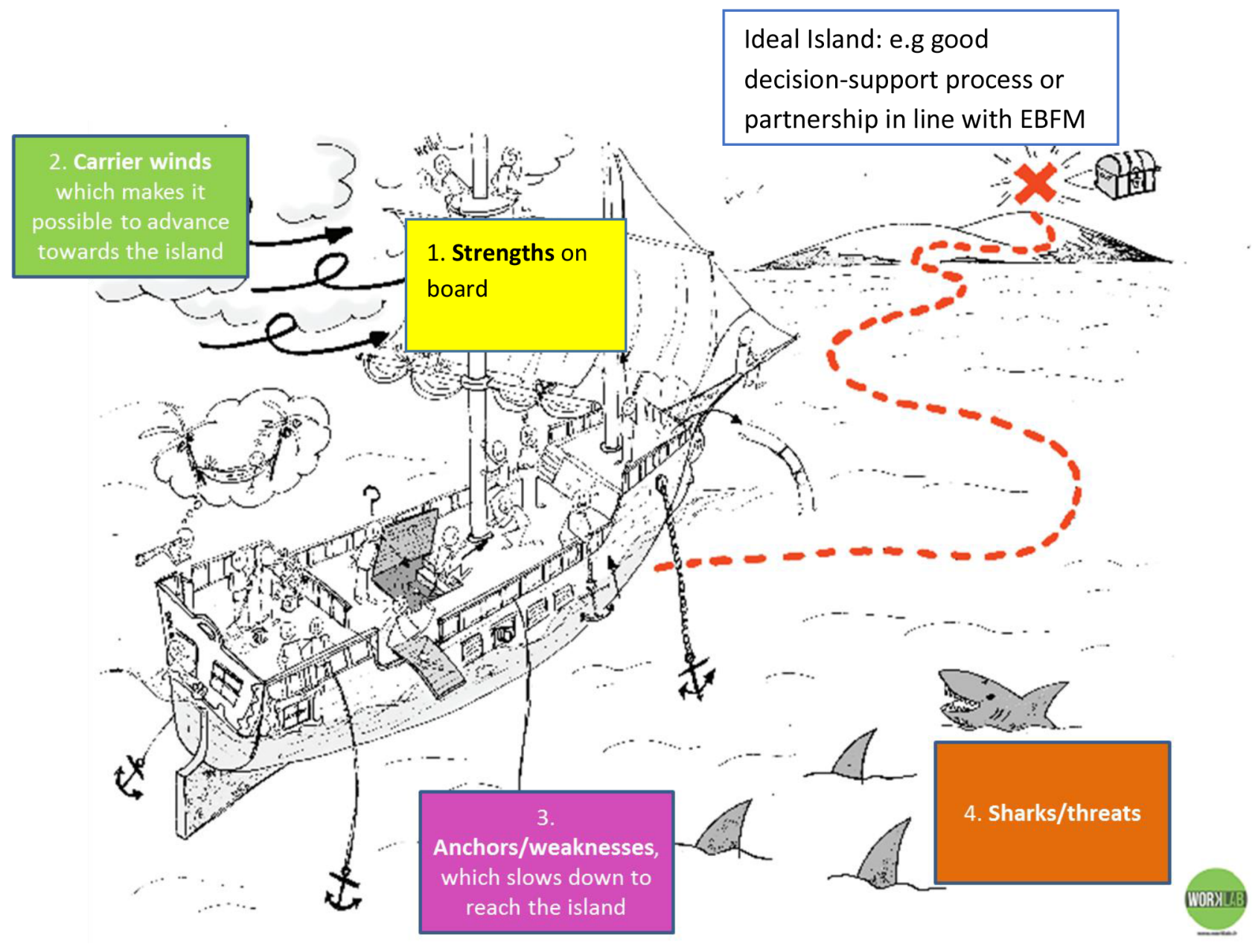

